\title{
Information and Assertoric Force*
}

\author{
Peter Pagin
}

October 10, 2010, 09:37

\section{Accounts of assertoric force}

An account of assertoric force is a theory that says what it consists in for an utterance to have assertoric force, i.e. to be an assertion. This is not exactly the same as being a theory which says under what conditions an utterance is an assertion, for there are different kinds of conditions, and only some of these matter to what we should call an "account".

Let's distinguish between surface properties and deep properties of utterances. I count observational properties as surface properties, and that includes e.g. prosodic properties such as stress and pitch. I also count as surface properties surface grammatical properties: word segmentation, word order, and surface morphology such as inflection markers. Among the "deep" properties are the mental state of the speaker, and contextual features like what norms or conventions are in force, and what the conversational setting is.

We can use this distinction to classify theories about assertion. Let's call a theory "superficial" if it just lists surface properties. Such a theory is correct if all and

\footnotetext{
${ }^{*}$ An early version of this paper was presented at the assertion conference in St Andrews. I am much indebted to comments at the conference, in particular to Herman Cappelen, Manuel GarciaCarpintero, John McFarlane, Francois Recanati, Robert Stalnaker, Jason Stanley, Michael BloomeTillman, and Crispin Wright. Several of these also provided valuable input in correspondence afterwords. I also later received valuable comments from Matti Eklund, Manuel Garcia-Carpintero, Carl Hoefer, Teresa Marques and Levi Spectre, as well as from two anonymous referees. As usual, Kathrin Glüer-Pagin has been an indispensable discussion partner throughout the process.

The work has been funded in part by a grant from The Swedish Research Council (Vagueness and Context Factors), and from the Spanish Ministry of Science and Education during a research stay in Barcelona (in the program Profesores e investigadores extranjeros de acreditada experiencia, en régimen de año sabático en España).
} 
only those utterance that have the listed surface properties are assertions. To my knowledge, no one has ever defended such a theory, and no such theory would be correct, for well-known reasons. ${ }^{1}$ Such a theory would not tell us what speakers are up to when making assertions, and I would not count it as an account of assertoric force.

Another type of theory, which we might call a "bridge theory", tells us the nature of the connection between surface properties and deep properties. A typical theory of this kind is that the connection is a matter of convention. Austin held that view (Austin 1975, 103), and it has also been advocated by Michael Dummett (Dummett 1981, 302, 311). ${ }^{2}$ A bridge theory by itself again says nothing about the nature of assertion, and I don't count it as an account of assertoric force.

A third type consists of theories that tell us what the deep properties of assertoric utterances are. Let's call these the "essence" theories. These theories do provide an account of assertoric force. They do it without appeal to surface properties. All main current accounts of assertion belong to this kind. The three main kinds are

(EA) a) Communicative intentions accounts

b) Institutional accounts

c) Norm accounts

Communicative intentions accounts all use ideas from Paul Grice's account of meaning (Grice 1957). Kent Bach and Robert M. Harnich (1979), and Francois Recanati (1987) have provided such accounts. Institutional accounts center on regulated social effects of making an assertion, e.g. the effect of having incurred a commitment, as suggested e.g. by Robert Brandom (1994), or having made a proposal, to be accepted or declined, for updating the common ground of a conversation, as suggested by Robert Stalnaker (1999, 10-11). Norm accounts, finally characterize assertion in terms of conditions of correctness, i.e. in terms of conditions of prop-

\footnotetext{
${ }^{1}$ Already Frege noted that utterances made during a theater performance aren't real assertions, despite having the typical characteristics.

${ }^{2}$ However, Donald Davidson $(1979 ; 1984)$ and others have argued that no conventional sign could work as a force indicator, since any conventional sign could be used (and would be used) e.g. in jokes and on the stage, where the corresponding force was missing.
} 
erly making assertions. The most well-known version of this today is the so-called knowledge account, associated primarily with Tim Williamson (1996, 2000). John Searle's account of assertion (1969) has elements of all three kinds.

For essence accounts the fact that there are surface properties associated with assertions does not play any role. We can add to the account simply that assertions are usually recognized by means of some correlation with surface properties, but on such accounts, that is inessential to being an assertion. ${ }^{3}$

The fourth and final type of theory is different in this respect. In this type of theory, surface properties are associated with certain intention-forming dispositions of the speaker and belief-forming dispositions of the hearer. The property of being assertoric then consists in the activation of these dispositions: either the disposition to produce an utterance with such surface properties only under certain conditions, or the disposition to react to utterances with these surface properties. Except for a brief suggestion of the present theory (Pagin 2008), no theory of this kind seems to have been proposed.

The present theory can be stated briefly:

(IA) An utterance $u$ is an assertion iff $u$ is prima facie informative.

The concept of informativeness can be roughly characterized as follows:

(IFN) An utterance $u$ is informative iff $u$ is made partly because it is true.

This is the basic idea. I shall spend most of the paper trying to work it out in some detail. Before embarking on that, however, I'll say a few words to motivate the attempt to come up with a new account. In earlier papers (Pagin 2004, Pagin 2009) I have argued that essence accounts of the two first kinds are false, since they will make utterances of some sentences come out as assertions (that $p$ ) while intuitively they are not. These sentences that provide counterexamples can be derived from the formulations of the accounts by means of performative constructions.

This form of argument does not work against the third kind of essence account.

\footnotetext{
${ }^{3}$ Recanati is to some extent an exception. He follows Sperber and Wilson's idea of making something manifest, i.e. perceptible or inferable (Recanati 1987, 120, 180; Sperber and Wilson 1995, 38), and has as a condition of making an assertion that the speaker makes it manifest that she has suchand-such an intention.
} 
Normative "accounts of assertion" have been widely accepted in recent years, with most of the discussion concerning differences between them. In the following section I shall argue that for the most part, these theories do not provide accounts of assertoric force in the present sense, and that norm accounts have very little plausibility.

\section{Norms of assertion}

Norm accounts of assertion are of the following general format:

(N) An utterance $u$ is an assertion iff $u$ is governed by norm $R$.

where $R$ is the norm proposed by the norm account in question. On this type of account, an utterance does not become an assertion in virtue of conforming to the norm $R$, and does not fail to be an assertion in virtue of failing to conform to $R$. It is the mere fact that $R$ applies to or is in force for $u$ that matters.

The first and still most supported norm account is what goes by the title 'the knowledge account of assertion', or 'the knowledge account', for short. ${ }^{4}$

The knowledge account involves a knowledge norm as the value of the $R$ parameter. In Tim Williamson's format, the norm is

(KA) One must: assert $p$ only if one knows $p$.

(Williamson 2000, 243; also followed by John Hawthorne $(2004,23)$ and Jason Stanley (2005, 10-11)). By (KA), if one asserts that there are craters on the moon without knowing that there are craters on the moon, one has made an incorrect assertion, and if one does know, the assertion is, in the proper respect, correct.

Others have criticized the knowledge account and proposed alternative norms. Instead of a knowledge requirement, Matthew Weiner (2005) proposes a truth requirement, Igor Douven (2006) and Jennifer Lackey (2007) a requirement of rational credibility (reasonable to believe), Jonathan Kvanvig (2008) similarly a requirement of justification strong enough for knowledge, and Jim Stone (2007) a

\footnotetext{
${ }^{4}$ Proponents include Peter Unger (1975), Michael Slote (1979), Timothy Williamson (1996; 2000), Per Martin-Löf (1998), Keith DeRose (2002), Steven Reynolds (2002), John Hawthorne (2004), Manuel Garcia-Carpintero (2004), and Jason Stanley (2005).
} 
context-sensitive rule by which knowledge is sometimes required but sometimes reasonable belief is enough. In all cases, a categorical knowledge requirement is deemed too strong.

Differences between these norms do not matter in this context. What matters is whether the account is or is not an account of assertoric force in the sense of section 1 . In the case of the knowledge account, as proposed by Williamson, this is clearly the case. Williamson favors the idea that the knowledge norm is constitutive of assertion in some mainstream sense of constitutivity (Williamson 2000, 238-43).

It is not as clear in all the other cases. You may hold on to a version of $(\mathrm{N})$ without claiming that it is in virtue of being subject to norm $R$ that the utterance $u$ is an assertion. You may hold that on the contrary, it is in virtue of being an assertion that $u$ is governed by norm $R$. You can still hold that all and only those utterances that are assertions are governed by that norm, but that what makes those utterances into assertions is something else.

Most of the discussion for and against the knowledge account has concerned the question which norm it is that governs assertion. It is not concerned whether assertion is essentially governed by some norm or other in the first place, nor whether, if so, it is in virtue of being governed by some norm that an utterance is an assertion. Here I shall not argue against the weaker claims that assertions are (essentially) governed by norms. If only the weaker claim is made, we still need some other account (normative or non-normative) of assertoric force.

Only the stronger claims are accounts of assertoric force properly speaking. On such theories, it is not in virtue of having any property that in itself makes the utterance into an assertion that the norm applies to the utterance. The question then arises: in virtue of what does it apply. For instance, in virtue of what property is Bill's utterance of

(1) The car weighs half a ton.

an assertion?

Let us compare with moral norms. Actions can be morally correct or morally incorrect, but we do not usually think that an event is an action in virtue of being 
morally evaluable. Rather, our normal outlook is that events are independently sub-categorized into actions and non-actions, and only the former are morally right or wrong. It is hard to make good sense of the opposite view.

With game actions it seems to be the other way round. It is not an intrinsic property of a certain piece of wood (or a certain type of screen image) to be a chess bishop. Rather, the wood piece acquires the property of being a bishop the moment you apply the relevant rules of chess, e.g. start a game, to the effect that the piece has the role of a bishop. In this case the rules of chess are constitutive of the property of being a bishop. The relevant rules must be in force for actions of moving the pieces around. Only when the rules are in force does the piece have the property of being a bishop, and the physical displacement of it the property of being a move. ${ }^{5}$

In the case of games, it is joint decision of the players to start a game, i.e. to let the rules of the game be in force under such-and-such a mapping between physical props and game roles. The players agree on the mapping and generally agree on the rules. If there is disagreement about the rules, this is treated as a factual question, something to be settled by appeal some authority, not something that is open to rational discussion.

To the extent that we evaluate assertions as being correct or incorrect, our practice resembles the practice of evaluating actions for moral qualities much more than they resemble a game practice. There seem to be no explicit decisions to let norms of assertion be in force, e.g. at the beginning of a conversation. If there is a question whether a particular assertion was right or not, there is no appeal to any antecedently agreed upon norms to settle the matter. And when the question arises what norms are valid, as in the debate just mentioned, participants argue with appeal to intuitions about cases and appeal to general principles, much as in debates about moral norms. This does not definitively refute the view that speakers have intentions to let some norm or other of assertion be in force for utterances, but it clearly shows, I think, that this view is highly implausible.

\footnotetext{
${ }^{5}$ For more on this conception of constitutivity, see Pagin 1987 and Glüer and Pagin 1999.
} 
It is not more plausible that convention take the role of intention here to attach the norm of assertion to the individual utterance. For if we have no general agreement of what the norms of assertion are, neither do we have any general agreement about what the conventions are that make norms of assertion apply to make an utterance into an assertion. Note that it is not at this point sufficient to say that we might have blank check convention $C$ that says: "Let whatever norm $R$ of assertion that is relevant be in force for utterance $u$ because $u$ has such-and-such characteristics". For the idea was that the utterance would be an assertion precisely in virtue of being governed by the norm. If being an assertion is constituted by a norm, and we don't know what the norm is, then we don't know what it is to be an assertion, and hence not what it is to be a "norm of assertion" either. Hence, no blank check convention can even make sense. ${ }^{6}$

Could there be some other way that a norm of assertion is made to govern utterances and thereby turns them into assertions? This cannot yet be excluded. But as long as no plausible account has been provided of what it might be, there isn't really any plausible norm account of assertoric force at all. Note that this holds independently of whether there in fact is a norm of assertion and whether, if so, that norm uniquely characterizes assertion as a kind of speech act. ${ }^{7}$

We can conclude, I think, that there is good reason to consider alternative accounts.

\footnotetext{
${ }^{6}$ Could it be that different speakers follow different norms? That is indeed possible, but since it is quite counterintuitive that speakers are performing speech acts of different kinds, rather than acts of the single kind of assertion, that by itself speaks against the constitutivity claim.

Could it be that speakers in fact intend a particular norm at a sub-personal level, without having cognitive access to this fact? This has been suggested to me by Manuel Garcia-Carpintero (pc). It could be, but it is not easy to make this plausible. For it is not enough to argue that some particular norm $R$ in fact governs assertion in virtue of conforming to our ordinary intuitions about correctness of assertions; it must also be argued that the ordinary speaker in fact intends $R$ to govern her utterance. It is not easy to see what an argument for that extra step could be like.

${ }^{7} \mathrm{~A}$ corresponding conclusion holds for the view that the concept of assertion is intrinsically normative (as suggested to me by Teresa Marques and Manuel Garcia-Carpintero), e.g. insofar as being an action type subject to some particular dimension of evaluation. A basic descriptive condition must be met in order for the concept to be applicable, and then the applicability of the normative concept supervenes on the satisfaction of that basic condition. It is the basic condition that interests me here, irrespective of my view that the concept of assertion isn't any more normative than action concepts in general.
} 


\section{Information and the information account}

To repeat, the information account can be stated as:

(IA) An utterance $u$ is an assertion iff $u$ is prima facie informative.

Spelling out what the condition of being prima facie informative amounts to will require some space. We need to say something about what it consists in to have the informativeness property prima facie, and what that property itself consists in. In order to explain that we need to say something about information in general and about representational content. In this section I shall focus on information.

From things we perceive we get information about other things, often things we haven't perceived. The presence of smoke gives us information about the existence of fire in the vicinity, the state of a window gives us information about earlier physical contact with some hard and solid middle-sized object. As a first approximation, I'll say that one event or contingent state of affairs $\alpha$ gives information about the obtaining of a distinct contingent state of affairs $\beta$ just in case the existence or obtaining of $\alpha$ tracks the obtaining of $\beta$, or again that $\alpha$ is produced by a process that reliably results in an entity of the relevant type of $\alpha$ just in case a state of affairs of the relevant type of $\beta$ obtains.

By 'tracking' and 'reliable process' I understand notions similar to those that have been employed in externalist epistemology, e.g. in Goldman 1979, and in information theoretic semantics, e.g. in Dretske 1981. A thermometer reliably gives information about the temperature of its immediate environment, since there is a nomic relation between the temperature and the state of the thermometer display. A clock reliably gives information about the time if its display is updated in a uniform rate in relation to standard time measurement. The actual time does not cause the state of the clock, but given a knowledge of the correlation between the standard time measurement and the clock display state at some time $t$, and knowledge of the rate of its change, knowledge of the standard time can be derived. ${ }^{8}$

\footnotetext{
${ }^{8}$ Gareth Evans' treatment of informational systems (1982, 122-29), as far as I understand, is completely focused on the causal model where the effect gives information about its cause. This conception is far too limited for present purposes.
} 
In general, if an event $\alpha$ of type A actually is a cause of an event $\beta$ of type $\mathrm{B}$, and it also is the case that in all or virtually all closest possible worlds where an event $\beta^{\prime}$ of type $\mathrm{B}$ occurs it is also caused by an event $\alpha^{\prime}$ of type $\mathrm{A}$, then $\beta$ gives information that an event of type A has occurred. ${ }^{9}$

This general pattern does not fit the clock example, and does not fit many other examples where one event can give information about another. We can e.g. get information about local rain in the near future from the presence of dark clouds and a drop of atmospheric pressure and temperature. The pressure drop isn't caused by the rain, but it is a regularity of sufficiently nomic character that under such conditions rain will result. We get information about a future state that is nomically almost determined by the current weather conditions.

The information channel can be more indirect. For instance, if I read off a barometer, the state of the barometer is caused by a state of atmospheric pressure, which in turn causally determines later weather conditions. Here the barometer state tracks the weather condition via a common cause, not via direct causation.

We even want to widen the concept of an information relation to cover abstract states of affairs. My pocket calculator gives me information about the result of, say, a particular square root operation. The fact that the display of the calculator gives 3,46 as an approximate (positive) result of the operation $\sqrt{12}$ gives me information about a mathematical fact. The state of the machine isn't caused by the mathematical fact, nor is there any common cause. Nevertheless, the machine reliably tracks the mathematical facts in the sense that there is mapping between machine display states and mathematical structures such that what is mapped from the input display of the machine is approximately equal to what is mapped from the output display.

Should we then drop the appeal to causality, and simply require e.g. that $p$ gives information about $q$ just in case the conditional probability of $q$, given $p$, is sufficiently high? This would not work in the mathematical case, since the conditional probability of a mathematical truth, given any state whatsoever, is $1 .{ }^{10}$

\footnotetext{
${ }^{9}$ We cannot appeal simply to the fact that $\alpha$ causes $\beta$ as long as the possibility remains that effects are causally overdetermined.

${ }^{10}$ With respect to a subjective notion of probability, say as degree of credence, this no longer holds. But here we want a concept of objective information, not a concept of trust in a source of possible
} 
Conversely, we could require that the conditional probability of $p$ given $\neg q$ is very low, but since in the mathematical case the probability of the negation of a mathematical truth is zero, that conditional probability would not even be well-defined.

If we switch from a probabilistic framework to possible-worlds framework, the result is similar. A requirement that $q$ holds in all the worlds or all the closest worlds where $p$ holds, is vacuous, since mathematical truths hold in all worlds, and a requirement that $p$ does not hold in worlds where $q$ does not hold is vacuous by the same token. Where $q$ is a mathematical truth, the condition is satisfied by any proposition $p$. If we only require conditions in terms of conditional probability or counterfactuals, we seem to lose the idea that we can get information from some contingent states of affairs but not from others, even though what we learn may be mathematically or nomically necessary. What is the way out?

The observation about the calculator case gives a hint about the general solution. We operate with a function $\mu$ between a domain $E$ of possibly informationgiving states of affairs and a domain $S$ of states of affairs of which information is given. We also have a method or type of process $\pi$ that is to secure the information. Then we can use the idea that among a large collection $E$ of possibly informationgiving states of affairs, all or almost all elements $e$ in $E$ that are generated or selected by means of $\pi$ are such that $\mu(e)$, a state of affairs in $S$, obtains.

In the calculator case, we have a large domain of possibly information-giving states of affairs consisting of the cartesian product of the set of possible input displays and the set of possible output displays, and under the intended function, most possible input-output pairs will be mapped on false mathematical propositions. The circuitry processing method $\pi$ is such that for a given input display (such as the sequence $\left\langle{ }^{\prime} 5\right.$ ', ' + ', ' 3 ' $\rangle$ ), it pairs a particular output display (' 8 '). The intended function $\mu$ will map that pair on a mathematical sentence or proposition. Those pairs that are in fact generated by $\pi$ will, in almost all cases, be mapped on true propositions. Hence the circuitry process $\pi$ reliably selects, with respect to the relevant function $\mu$, those pairs that are mapped on true propositions.

information. 
We cannot require that a method that gives information does so with nomic necessity, or else not much would count as information. There can be interfering factors that derange the process somehow. Of course, if the indicated state of affairs does not obtain, we don't have information about it either; the locution 'gives information that $p$ ' is factive. The problem is what to say about those cases where the process gets it right "by luck", so to speak. We would not want to say, without qualification, that we get information that $p$ from a process $\pi$ that in this particular case didn't work properly but by chance gave the right result anyway. This means that it is not, without qualification, sufficient to say that we get information from a particular state of affairs if what it indicates in fact obtains and the method of selection is reliable. This is a big question, and I cannot discuss it in full here. ${ }^{11} \mathrm{I}$ shall proceed under the assumption that we have a satisfactory qualification.

\footnotetext{
${ }^{11}$ We should distinguish between different cases. First, there is a case where the method doesn't work sufficiently well for certain tasks in $E$. For instance, a pocket calculator might systematically produce incorrect results for some type of inputs because of its rounding-off algorithms. In this case, we should say that the method isn't reliable for these inputs, but only for a subset of the original domain $E$.

Second, it may be that some operation $\delta$ that is sometimes involved in the application of the method $\pi$ is not sufficiently reliable, but tend to introduce errors when it is active. In this case it is really the sub-method $\pi^{\prime}$, without $\delta$, that is reliable. It is a further problem whether such a submethod can be specified in any effective way.

Third, there may be interfering external factors that introduce errors, reducing the reliability (conditional probability) from 1 to, say, $1-\epsilon$. These external factors are assumed to be random in relation to the $\pi$ process itself. In this case, we do get information on those occasions when there is no interference (even though the information user cannot know from the result alone that there wasn't any). The drawback is that we need a ceteris paribus hedge with the specification of the $\pi$ process. That is, when saying that information is given because a particular process $\pi$ that brought about a state of affairs is reliable, it is to be understood that on that occasion, the process was not subject to interference, although this will not usually be made explicit. This is analogous to the case of the explanatory status of theories with ceteris paribus clauses. A particular theory T can explain an event $s$ up to the ceteris paribus hedge, i.e. as far as the phenomena treated by $\mathrm{T}$ is concerned. It cannot explain why "other things were equal", but under the assumption that they were, T explains why $s$ occurred.

The third case should be distinguished from the case where the outcome of the $\pi$ process is stable, but the reliability is still only $1-\epsilon$, not because of chance interference, but because there is an inherently statistical correlation between the two kinds of states of affairs (in $E$ and $S$ respectively). In this case we do not, I think, get the information that a certain state of affairs $s$ obtains, but only the information that it obtains by a probability of $1-\epsilon$.

This is analogous to the explanatory status of an inherently probabilistic theory. If a theory $\mathrm{T}$ gives a high probability, say 0.9 , to the outcome $s$ of an experiment, and $s$ does occur, has the outcome been explained by T? Although several philosophers have answered in the affirmative (e.g. Wesley Salmon), I agree with Henrik Hållsten (2001, 57-67) that it hasn't been explained why this particular event belonged to the majority rather than to the minority.
} 
It will be convenient to regiment the terminology somewhat. Instead of referring to information-giving states of affairs, I shall speak of propositions about those states of affairs. That is, we have e.g. the proposition that

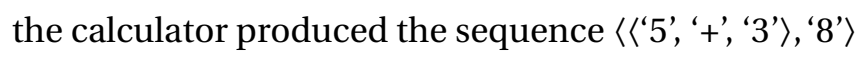

(i.e. the second element as output with the first element as input), or the proposition that

(3) the clock showed one o'clock at time $t$.

Similarly, we shall think of the $S$ domain itself as a domain of propositions. ${ }^{12}$ With this terminology, we shall say that the relevant function $\mu$ maps propositions on propositions, and that the relevant method $\pi$ makes certain $E$ propositions true, or selects them. For instance, we have a domain $E$ of smoke propositions (that there is smoke at location $l$ at time $t$ ) and a domain $S$ of fire propositions (that there is fire at location $l$ at time $t$ ). A smoke proposition is mapped by $\mu$ on the corresponding fire proposition. The method $\pi$, which is the generation of smoke, makes certain smoke propositions true, and thereby selects a certain subset $E_{\pi}$ of smoke propositions in $E$. The method is reliable to the extent that the set of fire propositions $\mu\left(E_{\pi}\right)$, the image of $E_{\pi}$ under $\mu$, has a sufficiently large fraction of true propositions. For ' $p \in E_{\pi}$ ' I shall write ' $\pi(p)$ '.

When we try to characterize reliability in terms of selections in a domain rather than in terms of modal properties of individual applications, it is essential that the domains $E$ and $S$ are such that the chance of selecting exactly the true-mapped propositions by chance is small. The idea of reliable selection will be vacuous if e.g. the $E$ domain only contains those propositions that are mapped on true propositions in S anyway. A minimal necessary condition for reliability is that the method $\pi$ does better than the degenerate method of selecting all propositions in $E$. For the main case, (propositions about) possible linguistic utterances, this condition is (in general) met. It is a very weak condition, but it will do some work later on.

\footnotetext{
${ }^{12}$ We might need to take into account more fine-grained entities than standard possible worlds propositions. In that case we will need structured entities that can be uniformly mapped on standard propositions. I shall assume that this move is available if needed.
} 
We shall say in general that a method or process type $\pi$ is $\mu$-reliable, meaning that $\pi$ reliably selects propositions in the domain of $\mu$ whose $\mu$ images are true, i.e. independently true. This means that if $\pi(p)$ and $\mu(p)=q$, then we do not also have $\pi(q)$; causing a proposition to be true is not giving the information that it true. Making use of this idea we could define the information relation along the following lines:

(I) A true proposition that $p$ gives information that $q$ iff it is true that $q$ and there are disjoint domains $E$ and $S$, a function $\mu: E \longrightarrow S$ and a $\mu$-reliable process type $\pi$ such that $\pi(p)$ and $\mu(p)=q$.

Note, finally, that I am not here making any epistemological claim by means of this account of the information relation. I do not here pronounce on the conditions under which an epistemic subject who comes to know that $p$ also acquires the knowledge that $q$. It may be sufficient that she knows that $p$ is made true by a reliable process with respect to a mapping on $q$, and infers $q$ from it. It may also be that something more is required, or something less. At present I am concerned with the conveying of information, not with the question how knowledge can result from getting it.

\section{Informativeness}

Some information-giving states or events are special because they represent the state they give information about. For instance, we can get visual information about a state of affairs from a picture that represents it, auditory information from a sound or sound production representing an earlier auditory event, and information of any kind from a linguistic utterance whose content represents what it gives information about. I shall say that the events or states of the latter kind, those that represent what they give information about, are informative.

A traffic sign, indicating that there is a railroad crossing ahead is informative in this sense, provided two conditions are met: i) that the process $\pi$ by which it got there is reliable with respect to a function $\mu$ that maps it on the relevant proposition, and ii) that the content of the sign can be said to represent that state of affairs 
or express that proposition with respect to the context, i.e. the location of the road sign.

Similarly, a thermometer display indicating that it is $15 \mathrm{C}^{\circ}$ is informative if it gives information about the temperature and the display represents the state of affairs, or expresses the proposition, that it is $15 \mathrm{C}^{\circ}$ in its immediate environment. A clock indicating that it is one o'clock is informative if it is correctly set, runs at the appropriate pace, and has a display that represents the state of affairs that it is one o'clock at the time of display. Finally, a linguistic utterance of

(1) The car weighs half a ton

is informative, with respect to a context, if the speaker is reliable in giving the weight of the car.

In these cases, the function $\mu$ from $E$ to $S$ is determined by a semantic function $\mu^{\prime}$. Consider again the example of a traffic sign, like:

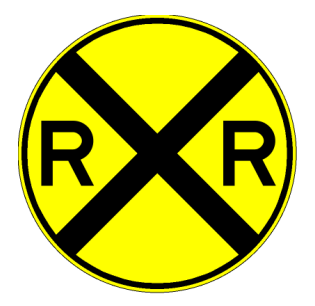

Figure 1: American traffic sign for road-railroad level crossing

This is an American traffic sign warning that there is road-railroad level crossing a short distance after the location of the sign (seen from in front). A semantic function $\mu^{\prime}$ takes as argument pairs $\langle R, l\rangle$, where $R$ is this sign type and $l$ is a location. It gives as value the proposition that

$$
\text { There is a road-railroad level crossing a short distance from } l{ }^{13}
$$

For every location $l$ there is a corresponding pair $\langle R, l\rangle$, and there is a function $\beta$ that maps each such pair on the corresponding proposition that

\footnotetext{
${ }^{13}$ The required distance from the sign to the intersection is a function the local speed regulations; around $110 \mathrm{~m}$ is a typical distance for an advance speed of $90 \mathrm{~km} / \mathrm{h}$.
} 
In this case the set $E$ of information-giving propositions is the set of "road sign" propositions expressed by (5), for variable $l$. The set $S$ of information target propositions is the set of "crossing" propositions expressed by (4), for variable $l$. Now it is clear that for any $l$,

$$
\mu(\beta(\langle R, l\rangle))=\mu^{\prime}(\langle R, l\rangle)
$$

That is, the function $\mu$ from $E$ to $S$ is determined by the semantic function $\mu^{\prime}$ together with $\beta$. We can say further in this case that $\mu^{\prime}$ is the intended interpretation. A particular road sign token at some location $l$ expresses the corresponding proposition $\mu^{\prime}(\langle R, l\rangle)$. We can regard the pair of a token sign and the location of that sign as an utterance in a wide sense of the term.

The process type $\pi$ in this case is the process type of being placed at a certain location (in the relevant way, not dumped in a storage space) by the Federal Highway Administration. We can regard this as a reliable process. With a negligible rate of exceptions, if a road sign proposition $p$ is made true and thereby selected by $\pi$, then $\mu(p)$ is true. A particular true road sign proposition $p$ is then informative, given that $\pi$ is reliable, in case $\mu(p)$ is true as well.

The road sign propositions, and in general the information-giving propositions in the relevant set $E$, are existentially quantified: such a proposition is true just in case there is some event or state of affairs with the relevant representational content that makes them true. The individual utterance, in the wide sense, is the witness that makes the proposition true. When we are concerned with utterances, i.e. with events that have an intended representational content, we can without loss of rigor speak of the utterance itself as informative. The utterance $u$ is informative just in case it is generated by a reliable process $\pi$, and $\mu^{\prime}(u)$ is true. Since we shall be concerned with linguistic utterances, we can then speak of the informativeness of such utterances. Instead of a domain $E$ of propositions about utterances we shall simply have a domain $E$ of possible utterances, and we shall use the semantic function itself as the map from $E$ to $S .{ }^{14}$

\footnotetext{
${ }^{14}$ This move is not available in the non-representational cases, like with smoke and fire, where we cannot separate the process that generates an event (like a smoke event) from the event itself in such
} 
Corresponding to a particular utterance $u$, there is an inference, with the premise that $u$ expresses some proposition $p$, and the conclusion that $p$. That $p$ is true is what $u$ gives as information. Let us use 'E(u,p)' as an abbreviation of 'utterance $u$ expresses the proposition that $p$ '. Then I shall call an inference of the following form

(II) $\quad E(u, p) \Rightarrow p$

an information inference. From the fact that a particular utterance is produced that expresses the proposition that $p$, it is inferred that it is true that $p$. The proposition that $E(u, p)$ is rendered true, under the interpretation, by the very process that produced the utterance $u$, e.g. placed a token of that particular road sign type at that particular location. I shall say that such an inference is informationally valid just in case the process $\pi$ that renders the premise true is $\mu$-reliable, where $\mu$ is the relevant semantic function. To the extent we can take the semantic function as given, we can simply say that $\pi$ is reliable.

It may be instructive at this point to compare the present idea of informativeness with Grice's distinction in 1957 between the natural sense of 'meaning', (meaning $\left._{\mathrm{N}}\right)$ and the non-natural sense of 'meaning' (meaning $\left.\mathrm{NN}_{\mathrm{N}}\right)$. Grice uses several criteria for making the distinction, but the main dividing line is the following:

(G) If $x$ means that $p$ entails $p$, then 'means' is used in its natural sense, and otherwise it is used in its non-natural sense.

(Grice 1957, 377-78). One of Grice's first examples is

(6) These spots mean measles.

(1957, 377). I think Grice's appeal to entailment involves the idea of a conceptual connection between having spots that mean measles in the natural sense, and having measles. If I don't have measles it is conceptually excluded that the spots I have mean, in the natural sense, that I have measles.

On that interpretation, the expressing relation encoded by $E(\cdot, \cdot)$ is not the re-

a way that it makes sense to speak non-trivially of a selection. 
lation of meaning that in the natural sense. It is allowed e.g. that a road sign at a location expresses the proposition that there is a railroad crossing shortly after the sign even though that proposition is false. However, I prefer to leave it open that at least in some cases, if an utterance $u$ means $_{\mathrm{N}}$ that $p$, then it also expresses that $p$ in the current sense. ${ }^{15}$

If we understand Grice's idea of entailment (perhaps unreasonably) only as the idea of a necessary conditional, then Grice's idea of meaning ${ }_{N}$ will almost coincide with informativeness. For then, to the extent that it is necessary that the conclusion of an information inference is true if the premise is true, to that extent the property of being informative with the content that $p$ satisfies Grice's condition of meaning $_{N}$ that $p$. Since I have wanted to allow a reliable process not to yield the relevant result by (nomic) necessity, informativeness will still include more

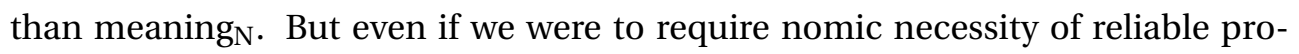
cesses, it would still be the property of being informative that would coincide with meaning ${ }_{N}$, not the property of expressing, by itself.

Grice wanted a distinction between two senses of 'meaning', or between two kinds of meaning, where the one is naturally given by causal regularities and the other most basically by communicative intentions. By contrast, I want in this context to remain neutral, as far as possible, on semantic questions. The concept of informativeness is not meant to define any particular concept of meaning. Specifically, it is not meant to define any information theoretic or otherwise naturalistic concept of meaning. I have used examples about clocks, thermometers and road signs, and these are clear candidates for giving information. That they also have representational content has only been assumed, it is not part of the main claims of the paper.

Linguistic utterances no doubt have representational content. And so a linguistic utterance $u$ with a propositional content that $p$ is informative just in case

\footnotetext{
${ }^{15}$ Cases where this might be plausible would be cases where the reliable production process actually serves to delimit the utterance type in question. For instance, the reverse side of a United States Nickel expresses the proposition that the coin has nominal a worth of five cents. We may take the coin itself to express this, at least provided it is genuine, i.e. produced and issued by the United States Mint. It is not so clear that a counterfeit Nickel can even be counted as an utterance of the same type, and then perhaps not even as expressing that it is worth five cents. If not, a coin's expressing that it is worth five cents entails that it is worth five cents. By Grice's standards, it means $\mathrm{N}_{\mathrm{N}}$ that.
} 
the information inference is valid for it, i.e. the process that resulted in $u$ is reliable with respect to the truth of the proposition that $p$. If $u$ is informative, then we can say that $u$ wouldn't have been made, or would only very improbably have been made, had it not been the case that $p$. The truth of $p$ is then an almost necessary condition for the production of $u$. It need not be a sufficient or almost sufficient condition. There may be many other factors, including reasons for the speaker, to make the utterance, over and above the fact that $p$. To repeat, this is intuitively summarized as:

(IFN) An utterance $u$ is informative iff $u$ is made partly because it is true.

The concept of informativeness will be applied in characterizing what it is for a speaker or a hearer to (explicitly, or implicitly) take an utterance as informative.

\section{Taking an utterance as informative}

Assertoric force will be characterized in terms of the attitudes of speakers and hearers to utterances. So it will not matter, for the individual utterance, whether or not it in fact is informative. What will matter is the attitudes of speakers and hearers regarding informativeness. We cannot assume that the average language user has en explicit theory about informativeness, or even a disposition to explicitly reflect on the idea. We have to look for something else.

Let's start with the hearer's side. Sue utters to Harry

The milk is sour

thereby saying of some particular quantity of milk that it is sour. We assume that Harry understands this utterance in accordance with the standard meaning of the sentence in English, and with the intended quantity referred to by the incomplete

description 'the milk', as somehow indicated in the context. As a result of hearing Sue's utterance, Harry comes to think the proposition that the milk is sour, and Harry also comes to believe that the milk is sour. We assume here that Harry either did not have any beliefs about milk status before, or perhaps believed the contrary up to hearing the utterance. 
We are interested here in Harry's transition from hearing Sue's utterance to believing that the milk is sour. This transition might take place in virtue of explicit reasoning, e.g. as follows:

(8) (i) Sue's utterance expresses the proposition that the milk is sour

(ii) Hence, the milk is sour

or more colloquially

(9) (i) Sue said that the milk is sour

(ii) Hence, the milk is sour

The inference (8) is an information inference of the (II) format, and the inference (9) is one too, implicitly, if we abstract from the explicit semantic component of the premise. Making the inference in reasoning is not precisely the same thing as judging that the inference is valid, but it can nevertheless be seen as tacitly endorsing that judgment. At least Harry would be incoherent in believing that he both makes the inference and that it is unjustified. So to this extent making the inference manifests a disposition towards accepting that it is valid, with respect to some type of validity or other.

The next question is whether accepting the validity of the inference involves believing that Sue's utterance is informative, i.e. intuitively that Sue made the utterance in part because the milk is sour. We cannot exclude the possibility that Harry had some completely different theory about why the truth of that proposition could be inferred from Sue's utterance, so that its truth would not enter in any reasonable way into the explanation of why Sue made the utterance. But we can simply decide to exclude such cases, since we are interested in understanding and characterizing the normal flow of utterances and attitudes.

That is, to the extent that Harry can properly be said to regard Sue's utterance as informative, in virtue of making an information inference, he would also be prepared to back up the inference in some such way, i.e. by explaining her utterance in part by reference to the fact that the milk is sour. Probably, and typically, such an explanation would proceed by way of explaining Sue's own belief by reference to 
her experience of the milk, and secondly her utterance by reference to her belief. That the milk is sour would be part of the explanation of why she comes to believe that the milk is sour from having the experience.

But Harry need not have the conceptual resources or the intellectual inclination for such explanations. Nor need he arrive at the conclusion by explicit reasoning. He is moved from believing that Sue said something to believing that what she said was true. What short of an explicit theory would show that Harry thought of Sue's utterance as informative? The answer can only be that his own belief-forming mechanism is sensitive to some relevant property of Sue's utterance. The property it is sensitive to might be the property simpliciter of being uttered by Sue, in which case Harry is prepared to believe anything Sue says. Perhaps the tone of voice is decisive. Again, it might be that Harry is inclined to believe what Sue says when he also believes that her belief is based on first-hand recent experience. Or perhaps, he is inclined to believe what Sue says when he also believes both that her belief is based on first-hand recent experience and that it is in her own best interest that Harry is correctly informed. And it might depend on yet other properties of the utterance.

The main point is that Harry's belief formation is sensitive to some features of Sue's utterance, such that he is in general disposed to believe that what she says is true in case he believes that her utterance has those features. In case of some surface properties, Harry may be inclined to believe that utterances have them just in case they actually do. With respect to some other properties, Harry's beliefs about Sue's utterance may be heavily influenced by his own background beliefs about Sue and the nature of the context. In either case, Harry's belief-forming mechanism is such that his disposition to believe that what she says is true is in general sensitive to properties he believes her utterance to have, call them $U_{S}$. This means that Harry has a disposition to treat $U_{S}$ as a reliability indicator. That is, he implicitly treats those of Sue's utterances that have $U_{S}$ as generated by a reliable process: he treats $U_{S}$ as a property that reliably selects true utterances.

We can recast this disposition as a standing subjective probability. Harry's con- 
ditional credence, or subjective probability,

$$
C_{H}\left(q \mid U_{S}(q)\right)
$$

that an arbitrary proposition $q$ is true given that it is the content of a $U_{S}$ utterance is high enough for outright belief.

Either way, that Harry implicitly takes Sue's utterance as informative does not require that Harry has any explicit theory or even any occurrent beliefs about informativeness, or beliefs that are explicitly about the relation between having certain utterance properties and expressing a true proposition. What matters is how Harry's own beliefs are formed. This is also what matters most even in case Harry does have an explicit theory. ${ }^{16}$

What about the speaker? In the most basic case, a speaker who makes an assertion simply expresses her belief. She may have various reasons for imparting her beliefs, but one of the reasons for asserting exactly that $q$ is that it is true that $q$. Suppose Sue's utterance of (7) is of this kind. Then we could explain Sue's utterance on a belief-desire model, to a first approximation, as follows:

(i) Sue wants to inform Harry about the status of the milk.

(ii) Sue believes that by saying to Harry that the milk is sour she informs him about the status of the milk.

This explains why Sue says to Harry that the milk is sour. ${ }^{17}$ The belief part (10ii) involves the belief that the milk is sour. Unless you count on a strange reasoning by the hearer, you cannot inform him that not- $q$ by saying that $q$, and we can assume in this case that Sue does not have any such expectations. So Sue's saying that the

\footnotetext{
${ }^{16}$ Because of definition (II), an event cannot give information about the truth of a proposition it causes to be true, the credence must be "intention-free". That is, in case of propositions about the future, the hearer must not believe that the proposition is true because he himself intends to make it true. If the hearer acquires the belief that he will by milk because of an utterance of 'You will buy milk', and this effect is mediated by his intention to buy milk, which is itself caused by the utterance, he will not be deemed to take it as informative, as long as he has some awareness that his belief depends on his intention and that his intention depends on the utterance. The corresponding restriction will hold for the speaker; the speaker will not take her utterance to be made in part because it is true for the reason that she expects that it will cause what it expresses to be true.

${ }^{17}$ We would of course need a further belief-desire explanation of why Sue chooses to utter the sentence (7) as a means for saying that the milk is sour.
} 
milk is sour is in part explained by her belief that the milk is sour.

From Sue's own perspective, things look different. In deciding to say that the milk is sour, she performs a piece of practical reasoning:

(i) I want to inform Harry about the status of the milk.

(ii) By saying to Harry that the milk is sour I will inform him about the status of the milk.

(iii) Hence, I shall say to Harry that the milk is sour.

This rationalizes Sue's saying to Harry that the milk is sour. The second premise is the doxastic one, corresponding to a belief of Sue's. The premise is not, however, that she believes that the milk is sour, but that the milk is sour. Only the fact that the milk is sour guarantees that saying that the milk is sour is giving information. So, from the perspective of Sue's decision making, she says that the milk is sour in part because, i.e. for the reason that, the milk is sour; that is, she says it in part because it is true.

This attitude is quite general. Whenever a speaker says something sincerely, i.e. says it in part because-from the third persons perspective-it is something she believes, she takes herself to saying it in part because it is true. But this means that she in general implicitly takes her own sincerely saying something as informative of its truth. By her own lights, the process that produces her sincere utterances tracks truth. She does not of course infer its truth from her saying it; rather, her decision to say it because it is true is, from her own perspective, a feature of her intention-forming mechanism. From Sue's perspective, the property of being sincerely uttered by Sue, is a property that selects true utterances. ${ }^{18}$

Hence, we can say that simply expressing one's belief is sufficient for implicitly treating one's utterance as informative. We can ascribe this decision-making process to any speaker that can be credited with having reasons for speaking. Hence, implicitly taking utterances as informative is a feature of both confident beliefforming and of sincere intention-forming mechanisms. No explicit theory or re-

\footnotetext{
${ }^{18}$ She will, if she is reasonable, admit that sometimes she makes mistakes, and therefore she would not make the general claim that everything she sincerely asserts is true. But she will still take it on each occasion that what she believes and considers on that occasion is true, and she will if rational believe in general that her rate of mistakes is low enough to keep on saying what she believes is true.
} 
flection is needed.

\section{Prima facie}

Assertions can be false. The speaker may be lying. The speaker may also be sincere but mistaken. Considering these possibilities, the hearer may in a particular case fail to trust the speaker. He may doubt that she is honest, or doubt that she is reliable. He may have such doubts even if she in fact speaks the truth, and even if she in fact is both honest and reliable. The reflecting hearer may know that she might be, and still doubt. And so on.

The hearer may have more or less well-founded reasons for doubting, but typically these reasons enter as restraints on an initial primitive impulse to believe. When Sue says that the milk is sour, Harry has an immediate impulse to believe that the milk is sour. He might after a moment's reflection hold back his credence, perhaps because the message conflicts with Harry's other beliefs, or because some doubt about Sue's reliability on the occasion. Still, he will have a first inclination to simply believe or to at least increase his credence. I shall here take it as an empirical datum that hearers typically have such impulses. With this datum as point of departure, I shall address some other questions.

a) Is it characteristic of assertion as such that the hearer has an impulse to believe?

b) How can we describe in purely doxastic terms what having such an impulse amounts to?

c) How does such a description fit in with higher-order beliefs and intentions?

I shall not here be concerned with the epistemology of testimony. That is, I shall not be concerned with the question under what conditions the hearer acquires knowledge from the speaker by coming to believe what the speaker says because she says it, or more generally to what extent the hearer's belief is justified when formed this way. However, question (b) is related, since it will be concerned with questions concerning the hearer's reasons for believing or not believing. 
To consider question (a), there is a strong intuitive connection between the idea of an impulse to believe and our conception of asserting, but not with our conception of other types of speech act.

To see this, consider the following utterance examples:

a. Bill claimed [asserted] that the sun is bigger than the moon, but he doesn't know anything about astronomy.

b. Bill asked whether the sun is bigger than the moon, but he doesn't know anything about astronomy.

c. Bill guessed that the sun is bigger than the moon, but he doesn't know anything about astronomy.

The second conjunct in (12a) is natural, for reporting that Bill had asserted appears something seems prima facie to imply that what was asserted could be worth believing because it was asserted by Bill, and precisely this implication is contradicted in the second conjunct. Without such a prima facie implication it is not clear how to account for the fact the contrast conventionally implicated by the occurrence of 'but' is immediately natural.

By contrast, the second conjunct in (12b) appears odd, and the natural explanation is that there is no prima facie implication in $(12 \mathrm{~b})$ that the proposition asked is worth believing, since Bill is reported only to have asked whether the proposition is true. Without such an implication the second conjunct has no natural relevance to the first, and therefore appears odd.

This oddity is to some extent shared with (12c). There is no inherent implication that a proposition guessed to be true is worth believing, and so it is not immediately clear why the second conjunct is relevant. However, in this case the contrast is less distinct. The reason, I believe, is that reading (12c) induces as a presupposition accommodation (in the sense of Lewis 1979). Some speakers are highly qualified on some topics, and on these topics even their guesses can carry some weight. If Bill is an expert on astronomy, his guess on some astronomical proposition might count in favor of that proposition. I think that in the case of (12c), the addition of the second conjunct tends to induce the accommodation 
that there had been an earlier presumption that Bill had substantial astronomical knowledge, to the extent that his guess should count. ${ }^{19}$ Still, there is some oddity, and it does seem that some extra operation, such as accommodation, is needed to remove it.

These simple examples are of course not conclusive as linguistic evidence, but they do point in the direction that it is characteristic of taking a proposition that $p$ as asserted that $p$ is also given prima facie credence, i.e. prima facie taken as true. In the sequel I shall assume that this is the case.

Before going on to characterize this property, there is a feature of the proposal that requires comment. Being prima facie $F$ is being prima facie $F$ to someone. An object $\alpha$ may be prima facie $F$ to $\mathrm{X}$ but not to $\mathrm{Y}$. This means that in the case considered an utterance $u$ can be an prima facie informative to $X$ but not to $Y$, and hence assertoric e.g. to the speaker but not to the hearer, or vice versa.

This may strike the reader as implausible. We are accustomed to treating 'assertion' as univocal, and the concept of being assertoric as one-place, i.e. nonrelational. We are also accustomed to think that the force of a speech act is determined solely by properties of the speaker, e.g. by the speaker's intentions. ${ }^{20}$ Treating assertoric to as a relation might then seem like a change of topic.

The short answer to this objection is that those who like may treat 'assertoric to' as a technical term introduced here, and regard the associated real concept of assertion to be that of assertoric to the speaker. That is not how I see it, however. Rather, I am interested in characterizing the primitive attitudes in which speaker and hearer, respectively, relate to an utterance as assertoric. The hearer may in fact have a more or less sophisticated theory of speech acts, and it may be part of that theory that whether or not the speaker really asserted anything only depended on the intentions of the speaker, or only on the communal norms in force at the time, or whatever. But if we think, as I do, that assertions (not just something with a cer-

\footnotetext{
${ }^{19}$ Of course, in this case, the proposition is too elementary for that presumption to have any credibility, but if the embedded sentence is replaced by one expressing something less elementary, (12c) is still different from (12a) with respect to the naturalness of the second conjunct.

${ }^{20}$ In fact, this was not exactly Austin's view. According to Austin $(1975,116-17)$, a speech act is successfully performed only if uptake is secured, i.e. only if the hearer is aware of the utterance and understands it in a certain way.
} 
tain similarity to assertions) are both made and acknowledged by unsophisticated speakers who don't have any conception of communicative intentions, commitments or communal norms, then we need to look for more elementary attitudes and attitude-forming mechanisms that are shared between the more and the less sophisticated. And when we are considering elementary attitude-forming mechanisms, the asymmetry between speaker and hearer cannot be disregarded.

Two quick comments can be added to this. First, as we shall see later, there are dissociation phenomena, where an utterance is, in my terms, assertoric to the speaker but not to the hearer, or vice versa. These cases are puzzling in their own right. What to say about them from the present perspective is fairly obvious, but they are more problematic from a perspective which treats the property of being assertoric as one-place only. This, I think, tells in favor of the present account.

Second, as we also will see below, it is a consequence of the present account that the properties of being assertoric to $X$ and assertoric to $Y$ will be virtually coextensive, in case $X$ and $Y$ are (normal) members of the same speech community. Dissociation will occur only as rare exceptions. Hence, the conceptual distinction will not matter for normal linguistic interaction.

The main question, however, is how to characterize the notion of being prima facie $F$ to a subject $X$. One alternative is to do it in terms logical property, or reasoning property, as suggested by John Pollock in 1974 and later works. He introduces the notion of a prima facie reason. A prima facie reason is a self-sufficient but defeasible reason $(1974,40)$. A reason is self-sufficient if it does not require more premises to justify the conclusion $(1974,34)$. Clearly, that a speaker asserts that $p$ is a defeasible reason for believing that $p$. It is less clear why it would be self-sufficient. Characterizing it as self-sufficient would be part of a theory of justification: it is prima facie justified to believe that $p$ given that it has been asserted that $p$.

In fact, this seems to have been the view on testimony suggested by Thomas Reid:

Testimony, at least sincere testimony, is always prima facie credible (Reid 1975, VI, xxiv). 
Reid's view is characteristic of what today is called "anti-reductionism" about testimony, i.e. the view that justification of testimony-based belief does not reduce to individual belief justification; you can be justified in believing what the speaker says even without having sufficient justification for the belief that the speaker is sincere and reliable (see e.g. Goldberg and Henderson 2006).

Here, however, I am not characterizing assertoric force in terms of the justification for believing what is asserted, but only in terms of dispositions to do so, insofar as the hearer is concerned. This suggests characterizing it in terms of $\mathrm{cre}$ dence, or subjective probability, rather than in terms of reasons or justification, even though there will be similarities between the normative (justification based) and the descriptive (credence based) accounts.

What we want are conditions $\Phi_{Y}$ and $\Phi_{Y}^{\prime}$ for the speaker and conditions $\Phi_{X}$ and $\Phi_{X}^{\prime}$ for the hearer, that meet the following two requirements:

(PF) a) $\Phi_{Y}$ and $\Phi_{X}$ are met by default and are characterized in terms of credence.

b) $\Phi_{Y}^{\prime}$ and $\Phi_{X}^{\prime}$ are met when the default conditions are not met but seem to be.

The basic idea is that the speaker/hearer meets the default condition, then he/she takes the utterance as informative. This together with the further condition that the default condition seems to be met, characterizes the idea of being prima facie informative.

Let's look at it first from the hearer's perspective. We want to characterize a phenomenon that can be loosely described as follows: the hearer $X$ gets an initial impulse to believe the proposition $p$ the speaker has asserted, and then modifies that impulse by taking into account background beliefs relating to the speaker (bearing on trustworthiness and reliability) and background beliefs relating to $p$. The resulting credence may be any degree between 0 and 1 .

What we are after is characterizing the initial impulse to believe. One thing we cannot do is to isolate a first stage of some initial credence level, followed by later stage where the level is adjusted. This would be sheer empirical speculation; there 
need be no such stage that can be isolated and correlated with a credence level.

It would be more adequate to abstract the contribution that being asserted makes to the hearer's belief. Then we reason like this. We have a credence function $C_{X}$ for $X$, i.e. a function that for any proposition $p$ assigns the degree of belief or subjective probability of $X$ with respect to $p$. As usual, a credence of 1 means maximal strength, 0 minimal (absolute disbelief) and 0.5 indifference. Further, there is a set of propositions $A^{X}$ that have been asserted to $X$ by some speaker or other. $^{21}$ Now we look at the elements $q$ of $A^{X}$, and for each element extract from $C_{X}(q)$ at some time $t$ the contribution that being asserted has made for determining that degree, call it the assertion factor. Then, we abstract from the contribution to each credence an assertion factor function $\alpha_{X}$ that for $X$ characterizes what role the property of being asserted makes to his systems of belief.

Such an abstract idea would involve heavy idealizing, for it is not so easy to know exactly what extracting the contribution of assertion would amount to. But there is another problem with the suggestion; it disregards the time of assertion. A proposition $p$ may have been asserted to $X$ at some time $t_{0}$. At later times, $t_{1}, \ldots, t_{n}$ $X$ has formed further beliefs that have had an impact on his credence in $p$. It may in fact be the case that although the assertion of $p$ once did make a difference to the credence of $X$, later information has made that effect insignificant, or completely obliterated it. Hence, at a later time the contribution may in principle not be extractable.

What we need instead is to focus on the transition from not being asserted to being asserted. We shall then need to distinguish a prior credence function $C_{X}$ before a particular assertion has been made from the posterior credence function $C_{X}^{\prime}$ after the assertion has been made. And it is natural to think of this transition as a Bayesian updating:

$$
C_{X}^{\prime}(p)=C_{X}\left(p \mid A^{X}(p)\right)
$$

That is, the posterior credence is the same as the prior conditional credence of $p$ on condition of having been asserted.

There are now two alternatives. Either we place a condition on the posterior

\footnotetext{
${ }^{21}$ I shall write ' $A{ }^{X}(q)$ ' instead of ' $q \in A^{X}$ '.
} 
credence irrespective of the prior credence, or else a condition on the the posterior credence in relation to the prior credence. It might seem that the first alternative is more plausible and also that it better captures the intuitive idea of prima facie informativeness. It would then be natural to set as the default condition that the hearer's posterior credence amounts to an outright belief in the proposition expressed, where outright belief (or "flat-out belief") is belief strong enough to act on. ${ }^{22}$ Let's say that for $X$ (in the context) outright belief amounts to a credence that is greater than some value $\epsilon_{X}$, where $\epsilon_{X}$ is at least 0.5 . Then we might place as the default condition:

$$
C_{X}\left(p \mid A^{X}(p)\right)>\epsilon_{X}
$$

This idea captures the impact of assertion at the time it is made, since the credence is the credence immediately before the assertion. ${ }^{23}$

\footnotetext{
${ }^{22}$ It has been objected against a credence-level notion of outright belief both that it makes outright belief context dependent, which is taken to be counterintuitive, and that for any level less than 1 it violates the conjunctive closure condition, that one believes in the conjunction when one believes in the conjuncts (cf. Frankish 2009, section 3), which is taken to hold for outright belief. Whatever notion of belief is connected with these intuitions, for the present concept of outright belief I accept context dependence and do not require conjunctive closure.

I shall propose three conditions for a speaker $Y$ in a decision context $c$. Let $a$ be the utility for $Y$ in $c$ to do $A$ in case it is true that $p, b$ be the utility for $Y$ in $c$ to do $A$ in case it is false that $p$, and $c$ be the utility for $Y$ in $c$ of abstaining from doing $A$. Let $b$ be non-catastrophic (i.e. not to be unconditionally avoided). Then we have the following conditions:
}

a) $\quad a>c>b$

b) $\quad 0.5(a+b)<c$

c) $\quad\left(C_{Y}(p) \times a+\left(1-C_{Y}(p)\right) \times b\right)>c$

I assume that preference follows expected utility. Then the second condition requires that $Y$ prefers abstaining if her credence is neutral between $p$ and $\neg p$ (to rule out that $a$ is too high) and the third that her credence in $p$ is strong enough for her to do $A$. Then we can state that

(OBL) $\quad Y$ has outright belief that $p$ iff: for any contextually relevant action type $A$, if i) and ii) are true for $A$, iii) is true for $A$

This idea is somewhat similar the so-called "assertion view" of belief in Kaplan 1996, 107-11, where Mark Kaplan requires preference for asserting that $p$ over the abstaining and asserting the negation, given that one is only interested in the truth.

${ }^{23}$ An alternative to the $(\mathrm{PF})$ schema is to require that $(\mathrm{OB})$ holds when all background beliefs have been filtered out. This would the case e.g. if what is asserted goes against once general knowledge of what is physically or technologically possible.

But a problem with this suggestion is that filtering out all relevant background information might simply be filtering out large parts of the belief system of the hearer, so much that what is left is incoherent. The hearer will need his general knowledge of the world even to recognize that an assertion has been made, and so much will have to be left intact anyway, but what is left will be relevant to 
One problem with $(\mathrm{OB})$ is that there may be variation, both between hearers within a community, and between communities, in how one reacts to a new assertion, given that one's antecedent credence is neutral. Some may be rather gullible, some may be in general very skeptical, requiring always more than a single testimony for outright belief in what has been said. ${ }^{24}$

We could avoid this problem by weakening the condition from requiring outright belief to requiring only minimal belief, i.e. a credence greater than 0.5 :

$$
C_{X}\left(p \mid A^{X}(p)\right)>0.5
$$

We assume that to primitively take an utterance as assertoric, given that one is antecedently indifferent to the proposition expressed, is to become more disposed to believing it. ${ }^{25}$ This then avoids the problem above, for if you are more disposed to believe that $p$ and less disposed to believe its negation, then you have a greater credence in $p$, and vice versa. And there can be no weaker requirement of credence increase than an increase from 0.5 to some value or other that is greater than 0.5.

Still, I think that (MB) is not fully adequate. With (MB) we would take the case where the hearer is antecedently indifferent as the default case. The hearer may antecedently disbelieve that $p$, and even if the disbelief in $p$ is weakened because of the assertion, the resulting credence may still be below 0.5 . We would have to include this case in the override conditions $\Phi_{X}^{\prime}$. But this would leave the general belief-boosting effect of assertions unaccounted for. It would leave out of the account precisely that the hearer's disbelief is by default weakened because of the assertion. Also, it would leave out of the account that by default, if $X$ already has positive credence in $p$, the posterior credence is higher than the prior credence

some assertions. The idea of just filtering out all background knowledge does not work. As was pointed out by John McFarlane, the admissible background knowledge cannot really be only what is known a priori.

${ }^{24}$ I am here indebted to Crispin Wright and Carl Hoefer. I in fact proposed the (OB) condition when giving the talk in St Andrews, and Wright objected. My reasons for not immediately giving up the condition had to do with issues of separating assertion from weaker types of utterance. This is discussed below.

${ }^{25}$ If you don't even have that, then no number of assertions that $p$ could make you believe that $p$ or even more disposed to believing that $p$. But that stance cannot be motivated by being more skeptical. If you are more skeptical than I am, the same evidence will move your credence less than it moves mine. If it doesn't move at all, then you are not skeptical but insensitive to the evidence. Not being moved at all by assertions is being insensitive to assertoric force. 
(belief is reinforced). Hence, the condition (MB) is not general enough.

It may then seem that it is rather the adjustment of credence after an assertion that is the crucial transition for the hearer. The default condition on beliefformation should then be stated as

(CA) $\quad C_{X}\left(p \mid A^{X}(p)\right)>C_{X}(p)$

This means placing as a condition that assertion in general has a belief- boosting effect. Typically, the hearer will have a stronger credence in a proposition after it has been asserted to him than before. We can see (MB) as a special case.

But this cannot be right either, for it is possible that e.g. $X$ is the hearer of assertions that $p$ over and over, and in accordance with (CA) has his credence in $p$ increased every time, even though it never reaches 0.5 ; it may asymptotically approach some lower value. This indicates that (CA) alone does not capture the idea of taking an utterance as prima facie informative. The main idea with (PF) was that under default conditions, the hearer (or speaker) does take the utterance as informative, which means implicitly accepting the information inference

$$
E(u, p) \Rightarrow p .
$$

If the default condition only requires a credence increase, then there is no obvious sense in which that inference is accepted, even though credence in informativeness is higher than credence in $p$ itself.

The conclusion is that we need both $(\mathrm{MB})$ and $(\mathrm{CA})$ together:

$$
\begin{array}{ll}
\text { i) } & C_{X}\left(p \mid A^{X}(p)\right)>0.5 . \\
\text { ii) } & C_{X}\left(p \mid A^{X}(p)\right)>C_{X}(p) .
\end{array}
$$

If $X$ has a belief-forming mechanism characterized by (BF), then $X$ in default cases implicitly has a confidence in the validity of (II) (credence in the proposition that the inference is valid) that both exceeds 0.5 and exceeds the credence in the proposition expressed. Thus, if $X$ already believes that $p$, then $X$ is prepared to believe even more firmly that an assertion by $Y$ that $p$ is informative. After the assertion, $X$ will have a reinforced belief in $p$. And if $X$ has a disbelief in $p$ prior to 
the assertion, in default cases the posterior credence is anyway at least a minimal belief. $^{26}$

If the default conditions are not met, then this is because there are overriding reasons against getting a positive credence, or a credence increase, or both. These reasons are of three main kinds:

(NI) a) $X$ is sufficiently convinced that $Y$ is unreliable or insincere with respect to $p$.

b) $X$ is sufficiently convinced that $Y$ does not have evidence for $p$ that adds anything to the evidence for $p$ that $X$ already possesses.

c) $X$ is sufficiently convinced that $Y$ does not have evidence for $p$ that detracts, or detracts enough, from to the counter-evidence that $X$ already possesses.

Let's start with (NIa), which applies irrespective of the hearer's antecedent credence. $X$ might be convinced that $Y$ as speaker is unreliable whatever evidence she in fact has, or at least that this holds for the case at hand. $X$ might believe that $Y$ has bad perception, or bad memory, is generally sloppy, or is bad at drawing correct inferences from evidence that she has. ${ }^{27}$ Because of this, the margin of error is so great that there is no reasonable way of adjusting credence because of the assertion. $X$ might also believe that $Y$ is not sincere. This might lead $X$ to infer the opposite of what $Y$ is saying, and in might lead $X$ to regard $Y$ as unreliable: $Y$ 's reasons for asserting that $p$ are not related to $Y$ 's credence in $p$, and so no conclusion about $p$ can be made. Finally, $X$ may be convinced that $Y$ does not have any

\footnotetext{
${ }^{26}$ The default conditions of (BF) can be met because they are mediated by a new intention of the hearer, caused by the utterance (as discussed in note 16), in case of orders or requests. This means that $(\mathrm{BF})$ characterizes prima facie informativeness only in case the hearer is not aware that that the new credence depends on an intention that itself depends on the utterance.

${ }^{27}$ In the Bayesian treatment of reliability of Bovens and Hartmann 2003, reliability is defined so that the conditional probability that a report that $p$ is made (REP), given that the report is reliable (REL) and the hypothesis that $p$ is true, is equal to $1(P(\mathrm{REP} \mid p, \mathrm{REL})=1)$, and correspondingly equal to 0 in case the hypothesis is false $(P(\mathrm{REP} \mid \neg p, \mathrm{REL})=0)$. It is treated as unreliable iff there is a fixed probability $\alpha$ that the testimony is made, independent of the truth value of the hypothesis that $p$ $(P(\mathrm{REP} \mid p, \neg \mathrm{REL})=P(\mathrm{REP} \mid \neg p, \neg \mathrm{REL})=\alpha)$. So in the unreliability case one learns nothing about the hypothesis from the report. If one knows that the report is reliable in their sense, one learns the truth value of the hypothesis. Reliability in my sense normally gives a conditional probability higher than 0 that the report is made given that the hypothesis is false, but this corresponds in their sense roughly to the probability that the report is unreliable.
} 
significant evidence, simply because such evidence is impossible or very hard to get, for $Y$ in particular or for anyone.

If the hearer has a background belief of these kinds, concerning $Y$ or concerning the availability of evidence, the normal credence adjustment will be blocked. The hearer will have no confidence in the validity of the information inference.

The other two cases, (NIb) and (NIc), are cases where credence adjustment, or minimal belief, is blocked because of the hearer's antecedent credence, or a combination of antecedent credence with belief about the evidence of the speaker. Under (NIb) we have situations where $X$ already has a maximal credence of 1 , e.g. because $X$ believes he already possesses a formal proof. We also have those cases where $X$ is convinced that $Y$ does not possess evidence that is different from his own, maybe believing it derives from the same source, say a newspaper article. In this case, (BFi) will be met, but not (BFii).

Under (NIc) we have the corresponding case where $X$ has a credence of 0 , e.g. because $X$ believes that he possesses counter-evidence that is maximally strong, and therefore discounts any evidence that $Y$ might have for $p$ as insignificant ( $Y$ will therefore be treated as unreliable). He might also believe again that he already knows the evidence that $Y$ has, and that this is outweighed by stronger counterevidence. In these cases, (BFi) is not met, and perhaps not (BFii) either.

What about the speaker? For the speaker $Y$, (BFii) does not make much sense. The speaker will not typically have a stronger credence in a proposition $p$ after she has asserted it than before. ${ }^{28}$ What matters for the speaker is the strength of belief in the proposition just before the assertion is made, not after, and so it should be characterized in terms of the prior credence function.

The speaker is prima facie expressing a belief, and so prima facie asserts that $p$ just in case she believes that $p$. The credence varies. Just as some hearers may be in general more skeptical than others, so some speakers may be in general more careful than others and require stronger evidence for unguarded assertions. Since outright belief is belief sufficiently strong for action (in the decision context) I think that we can simply equate having an outright belief that $p$ with having a disposi-

\footnotetext{
${ }^{28}$ It does happen that the speaker becomes more convinced after the assertion, but I shall not speculate about the possible explanations. It is anyway untypical.
} 
tion to assert that $p$, provided the speaker is sincere. This suggests the following simple condition for the intention-forming mechanism of the speaker:

$$
A_{Y}(p) \rightarrow C_{Y}(p)>\epsilon_{Y},
$$

where $\epsilon_{Y}$ is the outright-belief threshold for speaker $Y$ in the context, and ' $A_{Y}(p)$ ' means that $Y$ asserts that $p$.

The difference between (IF) and (BF) reflects the basic speaker-hearer asymmetry. For the hearer we consider part of the effect an assertion has, and for the speaker part of what causes it. (BF) and (IF) interlock in the sense that if the speaker has a sound belief-forming mechanism, then the two principles have the joint effect that the testimonial belief-forming mechanism of the hearer is sound as well. ${ }^{29}$

We can say in general that (IF) characterizes the intention of the speaker, unless the speaker intends to pretend to believe that $p$. Normally, the speaker pretends to believe that $p$ because she wants to mislead the hearer in one way or another, but that is not necessary. Normally, also, the speaker pretends to believe that $p$ because she pretends to say that $p$ for the reason that it is true, but she may pretend to have that reason even if she in fact believes what she says (she would have said it anyway).

So the utterance is prima facie informative for the speaker partly because the (IF) condition holds by default; only with a positive further reason for pretending is the condition violated. Partly, however, it is prima facie informative just because it is pretended to be informative, and hence made to seem like it is informative. This seeming-to-be informative is the topic of the next section.

\section{Surface properties and insincerity}

If an utterance of $p$ by $Y$ is prima facie informative to $X$, it is so because of some surface properties that $X$ observes and reacts to, and by default $X$ reacts to them

\footnotetext{
${ }^{29}$ Note that it is not required that the hearer acquires credence sufficient for outright belief, and hence not credence that is sufficient for going on go assert the proposition in turn. Hence, it is in accordance with (BF) and (IF) together that in a chain of assertions from one speaker to the next, credence peters out pretty quickly. Transfer of outright belief is not ruled out, however, and so the spreading of badly based beliefs is still in accordance with the account.
} 
by increasing his credence in $p$, to at least minimal belief. Such an utterance is characterized by certain grammatical properties of the sentence uttered ( it is normally an indicative sentence); a certain prosody (e.g. with declining pitch); and uttered with a certain serious facial expression and the gaze directed at the eyes of the hearer. Some variation is tolerated. Call this collection of features ' $\eta_{X}$ '.

Typically, the surface features that make an utterance prima facie informative to $X$ are pretty much invariant across speakers of the same speech community. It is possible that the community has some very deviant speakers, who don't sound at all like others, but such exceptions are rare. Especially in large speech communities where we often communicate with strangers, it is essential that we can recognize the force of an utterance by properties that are easily identifiable by observation. So we can expect that, mutatis mutandis, the same collection of surface features $\eta$ that make an utterance by $Y$ prima facie informative to $X$ also make an utterance prima facie informative to $X$ when made by virtually any other speaker $Z$ of the same speech community $C$.

But when this is true for some hearer $X$, it is likely to be collection of surface properties that make other hearers of the same community react the same way. That is, we can expect that for almost any two hearers $X$ and $X^{\prime}$ of the same community, $\eta_{X} \approx \eta_{X^{\prime}}$. If the differences are negligible, as we may assume, there is a collection of features for the hearer-community $C,{ }^{30} \eta_{C}$, and again it will then holds for almost every member $X$ of $C$ that $\eta_{X} \approx \eta_{C}$.

Being prima facie informative to a hearer $X$ for an utterance $u$ does not consist in having the features $\eta_{X}$, for an utterance not observed by $X$ can have them but will not be prima facie informative to $X$. Rather, as part of $X$ 's belief-forming mechanism $X$ has a disposition, characterized by (BF), to react to utterances that have $\eta_{X}$ by increasing his credence in the proposition expressed to at least minimal belief, and a particular utterance $u$ is prima facie informative to $X$ as hearer just in case $X$ 's reaction to $u$ is an activation of that disposition. ${ }^{31}$ Hence, an utter-

\footnotetext{
${ }^{30} \mathrm{~A}$ hearer-community is a speech community insofar as the members are considered as hearers.

${ }^{31}$ By having a disposition activated $\mathrm{I}$ here mean that there is a cognitive process in which the stimulus is recognized as meeting the conditions of the disposition, even if the further reaction to the stimulus that defines the disposition is blocked in that instance, by overriding background beliefs.

The idea is similar to D. M. Armstrong's idea (1993, 221-25) that perception induces an inclination
} 
ance $u$ is assertoric to a hearer $X$ just in case $X$ reacts to its surface properties by activating belief-forming mechanisms characterized by (BF).

We can give a more relaxed condition for being assertoric to a hearer-community $C$, since then it can only be the existence of the dispositions that matter. An utterance $u$ is then assertoric to a hearer-community $C$ just in case $u$ has $\eta_{C}$, the collection of surface features that makes members of $C$ as hearers disposed to increase credence to at least minimal belief.

Corresponding to the collection of surface features that makes hearers disposed to increase credence, there are surface features that are typical of sincere utterances. For a speaker $Y$, there is a collection $\sigma_{Y}$ of surface utterances such that normally, when $Y$ as speaker takes an utterance $u$ to be informative, $u$ has the properties in $\sigma_{Y}$. That is, when the speaker $Y$ makes a typical sincere assertion, the utterance has $\sigma_{Y}$.

As we reasoned above, we can assume that the surface features of sincere assertions in a speech community $C$ are pretty much the same as the surface features of utterance that hearers of $C$ take as prima facie informative. It is empirically out of the question that as hearers in a speech community the members would systematically misidentify the force of utterances made by members of the community as speakers. So, we can assume that for a typical speaker-hearer pair $Y$ and $X, \sigma_{Y} \approx \eta_{X}$, i.e. that surface features of prima facie informativeness are virtually the same for speaker and hearer. Since we assumed that surface properties for hearers are pretty uniform across members of the same speech community, it also follows that they are pretty uniform for the speakers, and it makes sense to assume a collection of surface features of the speaker-community: $\sigma_{C}$. Again, it is a consequence of the assumptions that $\sigma_{C} \approx \eta_{C}$, and hence that there is a col-

to believe what the senses present, even if overriding background beliefs block the realization. Armstrong faces the objection that in some cases the background beliefs block even the inclination itself, and meets it by appeal to the counterfactual claim that the subject would have acquired the belief had he not had certain other beliefs ( $p$ 222). But such a counterfactual need not be true (something else may have blocked the perceptual belief had it not been for the background beliefs), and it might be better for Armstrong to stick to the idea that there is an inclination, even when not available in introspection.

Note that I can say that a certain utterance simply isn't assertoric to the hearer even if it is e.g. assertoric to the speaker, but if a state is perceptual in the phenomenological respect, Armstrong cannot say that there is another respect in which it isn't perceptual to the subject because she fails to have the belief inclination. 
lection of features that characterizes utterance taken as prima facie informative in the speech community as such.

This fact is essential for the possibility of successful lying. An utterance isn't disqualified as an assertion because the speaker lies or because the hearer believes she is lying. A reasonable account of assertion must be robust with respect to these alternatives. The coincidence of surface properties across the community and between speaker and hearer is the key.

If speaker $Y$ deviates from the default sincerity, the most immediate alternative aim for $Y$ would be to make the hearer $X$ believe what is asserted, that $p$, even though $Y$ herself believes that it is false, or maybe is indifferent. Then $Y$ intends to make $X$ take $u$ as informative. $Y$ tries to make $u$ have those surface properties that normally make $X$ believe what $Y$ utters. We can assume that $Y$ implicitly believes that those surface properties are the same as the surface properties of sincere utterances by $Y$. Hence, $Y$ will try to make $u$ have the properties in $\sigma_{Y}$.

$Y$ may only intend to make $X$ believe that $Y$ believes that $p$ and takes $u$ as informative. In that case again $Y$ will try to make $u$ seem like a sincere utterance, and hence try to make $u$ have the properties in $\sigma_{Y}$.

$Y$ may be a more sophisticated liar, aiming only at making $X$ believe that $Y$ intends to make $X$ believe that $p$, while knowing that $X$ both knows that $p$ is false and that $Y$ herself does not believe it, but also believing that $X$ does not know that $Y$ knows these two things. Then $Y$ will try to make it seem to $X$ that $Y$ intends to make $X$ believe that $p$. When $Y$ does intend to make $X$ believe that $p$, as we saw, $Y$ tries to make $u$ have the properties in $\sigma_{Y}$. Therefore, $Y$ will try to make it seem that $Y$ tries to make $u$ have the properties in $\sigma_{Y}$. The only plausible way of making it seem that way is to try to make $u$ have the properties in $\sigma_{Y}$. Hence, $Y$ will try to make $u$ have the properties in $\sigma_{Y}$.

This generalizes. For any level of insincerity $n+1$, where $Y$ intends to make $X$ believe that $Y$ has the intention at level $n$, and trying to achieve the goal at level $n$ amounts to try to make the utterance have the properties in $\sigma_{Y}, Y$ will try to make it seem that she is trying to achieve the goal at level $n$, and the only reasonable way of doing that is actually trying to achieve that goal, i.e. trying to make $u$ have the 
properties in $\sigma_{Y}$. Hence, by induction, $Y$ will try to make $u$ have the properties in $\sigma_{Y}$ whatever the level of insincerity. ${ }^{32}$

In what sense does an utterance $u$ seem to be informative in case the default conditions are not met? In the philosophy of perception there is a distinction between an epistemic sense of 'seems' or 'looks' and a comparative sense. ${ }^{33}$ In the comparative sense of 'seems',

$$
\text { I seems like George has had a rough night. }
$$

would be paraphrased as

(14) George has manifest properties that are like those manifest properties he has when he has had a rough night.

Manifest properties are typically sensible properties, but at any rate properties that can be recognized by observation. What I have called 'surface' properties are manifest properties.

In the epistemic sense of 'seems', (13) can be paraphrased as

(15) George has manifest properties that provide evidence that George has had a rough night .

An utterance of (13) in the epistemic sense would normally also indicate that the speaker believes what seems to be the case, but that is more a pragmatic ingredient; what is essential is only that there is evidence.

The comparative and the epistemic senses are clearly closely connected, since manifest properties that are regularly caused by some non-manifest events also give evidence for the occurring of such events.

It is clear that when an utterance $u$ has both $\sigma_{Y}$ and $\eta_{X}, u$ has surface properties that are like surface properties of utterance that are taken as informative by $Y$ and $X$, respectively. It is also clear that for $X$, if an utterance $u$ by $Y$ has $\eta_{X}$,

\footnotetext{
${ }^{32}$ An intention to mislead is not a necessary condition for pretending, although it is typical. The intention to pretend, i.e. to make the utterance seem sincere, is the key, not the intention to mislead, which is only the common reason for pretending in this way.

For a related but different account of insincerity, see Owens 2006.

${ }^{33}$ This derives from Roderick Chisholm (1957, 43-53). Important modifications are due to Frank Jackson (1977, 30-33). (Thanks here to Kathrin Glüer-Pagin.)
} 
this does provide $X$ with evidence that $u$ is informative, whether that evidence is overridden or not.

It need not be the case that when $Y$ pretends to be sincere, the utterance seems informative to $Y$ in the epistemic sense, although that would be typical. Normally, if $Y$ pretends, $Y$ intends that the utterance have surface properties that provide evidence for $X$ that $u$ is informative. It is of course never the case that the surface properties give $Y$ herself evidence that the utterance is informative.

So, for $Y$, there is a clear sense in which both utterances that $Y$ in fact take to be informative and utterances that $Y$ merely pretend to take to be informative seem to $Y$ to be utterances that $Y$ take to be informative. And, as a normal speaker $Y$ has an intention-forming mechanism that by default is in accordance with (IF). That is, $Y$ has an intention-forming mechanism to produce utterances that have $\sigma_{Y}$ which is in accordance with (IF) unless $Y$ has reason to merely pretend that it is in accordance with (IF). ${ }^{34}$ Part of $Y$ 's intention-forming mechanisms then includes the disposition not to make an utterance $u$ that means that $p$ if $Y$ does not take $u$ as informative. When this disposition is activated, even if overridden by reasons for pretending, $Y$ makes an utterance that is prima facie informative to $Y$, i.e. an utterance that is assertoric to $Y$.

To sum up: for both speaker and hearer, an utterance is assertoric just in case it is prima facie informative. This characterizes the intention-forming mechanisms of the speaker and the belief-forming mechanisms of the hearer.

\section{Consequences of the account}

Now that the account is in place, I shall comment on some of its consequences.

Normativity and naturalism. In the present account, no appeal has been made to norms. The principles (BF) and (IF) are not normative but descriptive.

\footnotetext{
${ }^{34}$ It may be less obvious that this holds for the extreme obsessive liar who never utters a sentence for the reason that it is true. But such an obsessive liar is possible only because of believing that virtually every other member of the obsessive liar's community has such an intention-forming mechanism, and the obsessive liar intends to make his or her utterances have the property $\sigma_{C}$ that marks sincerity in the community $C$. The liar believes then that his utterances would have $\sigma_{C}$ if he were to be sincere, and hence that whenever the liar $Y$ would make a sincere utterance, $\sigma_{Y}$ would be equal to $\sigma_{C}$. Then, the obsessive liar has an intention-forming mechanism to make utterances that have $\sigma_{Y}$ only when $Y$ wants to make it seem that $Y$ actually takes the utterance as informative.
} 
Neither is it part of the account that assertion as a linguistic institution or practice has the purpose of conveying information. On the other hand, nothing in the account contradicts such a claim either. Similarly, nothing in the account precludes the possibility that norms of assertion are in fact adopted by the linguistic community. It is natural for speakers to take normative attitudes to actions by which they may be served but by which they may also be misled. However, there is no norm that is the obvious choice as norm of assertion, to be derived from the present account. $^{35}$

The present account has the character of "de-intellectualizing" assertion, insofar as no conceptual sophistication is required of speaker or hearer. But that in itself does not make the account naturalist. The concepts of belief and intention are freely made use of.

Speech act distinctions. Does the present account distinguish as desired between types of utterance. Consider the utterances of the following sentences: ${ }^{36}$

(16) Can you meet my sister at the train station?

(17) Is Canada, perhaps, a banana republic?

(18) John's father.

(19) a. How exciting that Jamie is coming for a visit!

b. It is exciting that Jamie is coming for a visit.

c. I am excited that Jamie is coming for a visit.

a. I have seen with my own eyes that Henry is bald.

b. I know that Henry is bald.

c. I believe that Henry is bald.

d. I guess that Henry is bald.

(21) I guarantee that people will pay more than 300.000 pounds for this apart-

\footnotetext{
${ }^{35}$ David Lewis's (1975) idea of conventions of truthfulness and trust in language $L$ has obvious parallels to the present account. According to Lewis, it is the choice of $L$ that is variable and conventional. The status of truthfulness and trust themselves in Lewis's account is less clear.

${ }^{36}$ It is also of interest to consider Moorean sentences like 'It is raining but I don't believe it'. In Pagin 2008 an account of Moore's paradox based on the information account of assertion is proposed. The main idea is that such an utterance is uninformative if true (an information collapse). More particularly, if the right conjunct is true, the (utterance of) the left conjunct is not informative.
} 
ment.

Your ticket did not win.

A typical utterance of (16) has interrogative force, but carries the presupposition that the speaker has a sister. ${ }^{37}$ Hence, the hearer will get the information from the utterance that the speaker has a sister. By the definition of informativeness, however, the utterance cannot be informative with respect to the proposition that the speaker has a sister, since it does not express that proposition but a different one. Nor will speaker or hearer (unless because of special circumstances) take the utterance as informative with respect to the proposition that the hearer picks up the speaker's sister from the train station. ${ }^{38}$ The hearer may nevertheless increase his credence in the proposition that the speaker has a sister from e.g. indifference to outright belief, and this may even be the default effect of utterances with presuppositions. Hence, there need be no difference between asserted propositions and (openly) presupposed propositions with respect to belief-formation and intention-formation. The only difference will be the semantic content of the sentence. This seems to me the correct result.

We have a corresponding conclusion for (17). The semantic content of the rhetorical question is that Canada is banana republic, but what is conveyed, and indirectly asserted, is the negation of that content. The belief- and intentionformations work as assertoric on the negation, but not on what is negated. This is intuitively an indirect assertion, made by means of what is directly a question. However, rhetorical questions do not automatically qualify as assertions on the present account. For suppose, as seems true, that rhetorical questions can be both affirmative and negative. We can surely often recognize questions as rhetorical on

\footnotetext{
${ }^{37}$ The question was raised by Michael Bloome-Tillman and the example is his.

${ }^{38}$ In fact, it may be that both the speaker and the hearer will increase their credence in the proposition that the hearer will pick up the sister after the question has been asked and before the answer has been given. The speaker may be correctly convinced in advance that the hearer will oblige. In fact, this may even count as the default case for requests (of this kind). Will it then be prima facie informative to speaker and hearer? No. The utterance cannot be informative, unless by very unusual circumstances. Typically, the utterance will cause the hearer to comply with the request, and by definition it cannot then count as giving information about the compliance (see paragraph before (II)). If the hearer is aware that the belief is mediated by his own intention, itself caused by the utterance, he will not count as taking the utterance as informative. See notes 16 and 26.
} 
the basis of surface features. But if we could only judge whether the speaker was affirming or denying the content on the basis of an independent judgment of the obvious truth or falsity of the proposition (or whether it must seem obvious to the speaker), then there would be no surface features of an utterance which together with the semantics of the sentence (in context) that would have a prima facie effect on the hearer's credence. For the hearer would then first have to take a stand on the plausibility of the proposition that is the immediate content of the question. This would make it impossible for instance to inform a hearer by means of a rhetorical question of something to which the hearer is antecedently neutral.

The situation is better with respect to some forms of utterance that do signal the speaker's stance, as the occurrence of the discourse particle 'perhaps' does in (17). So, it seems to me that some rhetorical questions can qualify as indirect assertions. $^{39}$

Next, an utterance of (18), together with pointing at man, would naturally convey the information that the man pointed at is John's father. Would this not be an assertion, despite not having the typical surface properties of assertions? For instance, the expression used is not even a full sentence. Robert Stainton has used such examples to argue against the claim that the practice of assertion relies on conventions that correlate force with sentence types. ${ }^{40}$ Examples like these could be similarly used to argue against the need of typical surface properties, even without the appeal to convention.

There are two points to be made in response. The first is to concede that there is an admissible variation in surface properties, and the use of demonstration without a demonstrative is clearly within established practice. In this case, the noun phrase 'John's father' is used to relate a property to the object demonstrated, but it is not made explicit which property (it might have been the property of having been beaten up by John's father). This has to be clear from the context. But that is not unusual. Rather, this kind of saturation of conceptual fragments into full propositions is already part of normal pragmatics. As has been argued by

\footnotetext{
${ }^{39}$ Here I am indebted to Manuel Garcia-Carpintero as well as to Kathrin Glüer-Pagin. Also, an earlier treatment of this example was adequately criticized by an anonymous referee.

${ }^{40}$ The example is taken from Stainton 1997.
} 
Barbara Partee (1997) and others, the genitive construction itself, exemplified by 'John's father', is a case in point, since we need to supply a relation between the denotations of the head noun phrase ('John') and the modifying noun ('father'). In this example it is standardly the kinship relation, but other interpretations are possible. As long as what is needed pragmatically to determine the content of the utterance does not go beyond what is often needed even in uses of syntactically complete sentences anyway, it is most plausible to count the utterance as an assertion, with surface properties that are within the range of normal variation.

The second point concerns cases where this condition is not met, as in pure gricean communication. For instance, $X$ has to figure out why $Y$ puts a finger to the tip of his own nose, and perhaps comes to the conclusion that $Y$ wants $X$ to believe that $Z$, who often complains about smells, has been invited as speaker, and wants him to believe this for the reason that $Y$ wants him to believe this (and so on). Examples like these lack a feature that is typical of assertions and other normal speech acts: the force and the content of the utterance can be determined independently, to a very high degree. This is certainly the case with normal assertions: the hearer can process the sentence semantically in relative independence of recognizing the surface features typical of assertion (syntactic parsing is presumably shared between the two processes). It is more contentious to claim that this separation of force and content is also a necessary condition of being an assertion. Notice, however, that the default effect on the hearer credence also depends on a condition that we haven't discussed: that the hearer's credence in the correctness of the interpretation is high. Too much uncertainty about interpretation will block the boost of credence in the asserted proposition. Hence, it is reasonable to think that a practice of assertion can exist only where there is a robust means of identifying utterance content, whether productive (of new contents) or primitive.

It may seem that the three sentences in (19) express the same proposition, that the speaker is excited that Jamie is coming for a visit, and give the same information. (19a) is clearly not an assertion, while (19c) clearly is, and so it may seem that the present account does not manage to separate non-assertions from asser- 
tions in examples of this kind. ${ }^{41}$ I do not think, however, that either (19a) or (19b) do express a proposition. Rather, they are, in different moods, expressions of an evaluating attitude or taste. The content is a propositional function that requires a standard of appreciation or taste to make a complete proposition. Such a standard is provided in (19c), where the standard of the speaker is explicitly supplied. Although there isn't space to argue for the claim here, I think that the proper conclusion of recent discussions of relativism regarding statements of personal taste is that the contents of such statement are not possible objects of belief, and since objects of belief are propositions, these contents are not propositions. If this view is correct, as I think it is, only the assertoric utterance of (19c) has the propositional content suggested. Utterances of (19a) and (19b) do not have propositional content, and hence are not assertions, even though they give the same information about the speaker as an assertion of (19c).

With the four sentences in (20) four utterances can be made, where the typical credence-boost on the hearer would vary from very strong, in (20a), to very weak, in (20d). We can assume that an utterance of (20a) or (20b) will have a stronger effect on credence than the corresponding utterances of the embedded sentences by itself ('Harry is bald'). Similarly, we can assume utterances of (20c) and (20d) will have weaker effects. The question is, however, whether the default conditions (BF) and (IF) are not also met by the embedded versions. In that case we cannot use these conditions to characterize the assertion that $p$, for the corresponding declaration that the speaker believes that $p$ is not an assertion that $p$ but would meet the default conditions nonetheless.

There is not really a problem with the stronger versions, since because of the factivity of 'see' and 'know', the embedded sentence is entailed (and the speaker could be said to indirectly assert what is obviously entailed by what she asserts). Hence, that utterances of (20a) and (20b) meet the default conditions with respect to $p$ is predicted by the account. ${ }^{42}$

The embedded sentence is not entailed in the weaker cases (20c) and (20d),

\footnotetext{
${ }^{41}$ The point is made by an anonymous referee, and the examples (19a) and (19c) are the referee's.

${ }^{42} \mathrm{By}$ the account, they are still not assertions that $p$, and so the default conditions do not uniquely characterize assertion that $p$ but rather assertion of some $q$ from which it obviously follows that $p$.
} 
however. Intuitively, if a speaker says that she believes that $p$, there is no presumption that she says so partly because it is true that $p$; the utterance is not (except in very unusual cases) prima facie informative with respect to the proposition that $p$. If the default conditions are still met, they do not characterize the very idea of prima facie informativeness.

I do not, however, expect that the default conditions are met. In general, the speaker who utters (20c) or (20d) has a credence in $p$ that is weaker than an outright belief, despite being sincere. Only a minimal belief in $p$ would be required for a sincere self-ascription of belief in $p$. Similarly, for the hearer, we would not expect that typically the default reaction to a self-ascription of belief in $p$ would be to increase his own credence to at least a minimal belief in $p$. Rather, the fact that the speaker self-ascribes belief that $p$ rather than asserting it gives reason to think that that the speaker is not reliable with respect to $p$, and so a credence-boost would occur only in case there is reason to have strong confidence in the speaker. ${ }^{43}$

Does this hold as well for cases like (21)? Here the utterance is designed to boost credence in $p$ without actually saying anything that entails that $p$ ? Similar cases would be 'I bet you a million that $p$ ' and 'I swear that $p$ ' ${ }^{44}$ By definition, these utterances are not prima facie informative of the proposition that $p$ expressed by the embedded sentence (in the context), since the utterance as a whole does not express it. But again, if the default conditions (BF) and (IF) are met by such utterance types with respect to $p$, then prima facie informativeness is not well characterized by these conditions.

Utterances of this kind tend to increase the credence of the hearer by way of a statement from which it is meant to be inferred that the credence of the speaker is very high, and that the speaker is reliable. Strictly speaking, then, it is only with the added premises (often tacit) that the speaker's credence $i s$ very high and that the belief is reliably formed, that the hearer infers that $p$ and his credence hence moves as intended. We can then conclude that since further beliefs on the part

\footnotetext{
${ }^{43}$ There is a further reason why (BF) does not give a default condition for (20c). See the discussion of (21) below.

${ }^{44}$ I have argued in Pagin 2004 and Pagin 2009 against communicative intention and institutional accounts of assertion that they would wrongly count as assertions that $p$ utterances of sentences that do not entail that $p$.
} 
of the hearer are required in order to satisfy (BF), (BF) does not characterize a default condition for utterances of this type. For the default condition holds unless it is overridden, and a hearer that is simply indifferent about whether the speaker believes that $p$ or about whether that belief is reliably formed does not have any overriding beliefs but still will not increase credence in $p$. Even if the required further beliefs about the speaker's beliefs are usually in fact produced in the hearer, that does not make having them a default condition, as long as the hearer might simply fail to have them without any overriding cause.

The sentence

Your ticket did not win.

has been used to argue that only knowledge provides proper warrant for assertion. The argument seems to be due originally to V. H. Dudman $(1992,205)$, but has been made better known by Williamson. In Williamson's version, the argument considers a (fair) lottery (Williamson 2000, 246-49) with a large number of tickets. It is known that only one ticket wins. B has a ticket. The draw has been held, but neither A nor B knows the result. A asserts (22) on merely probabilistic grounds. The probability that B's ticket won is very low, and one can get it arbitrarily low, short of zero, by increasing the number of tickets in the lottery. An assertion of (22) in such a case is intuitively flawed. According to Williamson (2000, 246), A is criticizable, since A represented herself as having an authority for the assertion which she lacked. The conclusion is that only knowledge provides proper warrant, since no probability short of 1 escapes the criticism for lack of authority.

The information account offers an alternative explanation: the utterance of (22) is not informative. The evidence used by the speaker corresponds to a method $\pi$ of selecting propositions of the form "Ticket $x$ did not win", where $x$ ranges over tickets in the lottery, or over tickets in any lottery where the chances of winning are equally low or lower. $\pi$ is coextensive with the degenerate method of selecting all relevant propositions, and hence does not meet the minimal necessary condition of section 3 on reliable selection. The conditional probability that a proposition is true given that it has been selected by $\pi$ is very high, but that depends entirely 
on the trivial fact that very few of these propositions are false. $\pi$ is not sensitive to facts about the outcome of the lottery, and hence being selected by $\pi$ does not give information about it. Since the utterance is prima facie informative but not informative, the speaker A does in a sense, as Williamson says, represent herself has having an authority that she in fact lacks. But the conclusion that only evidence that gives a probability of 1 suffices for proper warrant is not immediately warranted, since a reasonable alternative and non-ad hoc explanation of the intuitive defect of the assertion is available.

Dissociation. In abnormal cases an utterance is assertoric to the speaker but not to the hearer, or vice versa, and the two properties are then dissociated. There are trivial examples where the hearer simply mistakes the force of the utterance, perhaps because of not paying full attention to the utterance. But there are also more interesting cases. Let's say that we have speaker failure when the speaker does not take her utterance as prima facie informative but the hearer does, and that we have hearer failure in the opposite case. Let's start with the latter.

A possible case of hearer failure would would occur in connection with a speaker $Y$ whose belief-forming mechanism seriously malfunctions. After some experience with $Y$, the hearer $X$ concludes that there is no more than random correlation between propositions asserted by $Y$ and truth. $X$ believes, correctly, that $Y$ 's utterances are sincere (and hence that, in some sense, they are assertions), but default reactions are overridden by knowledge of $Y$ 's unreliability. After some time, the natural reaction might completely wear off: $X$ no longer has any inclination to increase credence because of $Y$ 's utterances, even though still taking them to be believed-true by $Y$. What is the proper characterization of $Y$ 's utterances? Are they assertions? On the present account, they are assertoric to the speaker but not to the hearer, and over and above that, we are free to stipulate what to call 'assertion' simpliciter.

A different case ${ }^{45}$ would be a hearer $X$ whose natural reactions are turned-off (because of some strange wiring in his Wernicke's area) when hearing utterances in a Scandinavian accent. In this case $X$ does not think that Scandinavians are un-

\footnotetext{
${ }^{45}$ This example was suggested by by Herman Cappelen as indicating that focusing on primitive reactions has counterintuitive consequences.
} 
reliable, but on the contrary normally infers that what has been uttered is true. It is just not the default reaction. Can we say that $X$ does take the Scandinavian utterances as assertions? Indeed, because $X$ infers that what has been uttered is true, we must assume that $X$ takes the utterances as expressions of belief, and hence implicitly as assertoric to the speakers. $X$ is therefore justified in treating them as assertions in this sense, despite the fact that as matter of primitive reaction, they are not assertoric to $X$.

As a case of speaker failure, consider Wittgenstein's train announcer (Wittgenstein 1980, $\$ 486$ ), who says

$$
\text { Train No ... will arrive at ... o'clock. Personally I don't believe it . }
$$

If it were just a matter of announcing trains without believing the announcements, the utterances would still appear prima facie informative to the speaker. The addition of the belief-denying second utterance removes that feature. Still, the hearer might well react by believing what is announced, thinking that it does not matter what the announcer personally happens to think. Does the train announcer assert that the train is coming in? Maybe it is not so clear, but again it is clear what to say on the present account.

A different case ${ }^{46}$ concerns a person $Y$ who is practicing English alone by reading from an encyclopedia. $X$ overhears $Y$, knows what $Y$ is doing, knows what the source is and trusts it. Hence, $X$ in fact takes $Y$ 's utterances as informative. In this case, the utterances are not prima facie informative to $Y$, for there is no sincerity pretense. Hence, the utterances are not assertoric to $Y$. Are they assertoric to $X$ ? Assume that $X$ does not in this case have an atypical psychology. The typical hearer reaction would be not to take the utterances as prima facie informative, since there is no normal speech situation, and hence not all normal surface properties of the utterances are instantiated. The effect they have on credence for $X$ depends on background beliefs, not on the property alone of being uttered in such and such a way by $Y$. So they are not assertoric to $X$. Again, this seems to me the intuitively right outcome.

\footnotetext{
${ }^{46}$ This example was provided by John McFarlane, who suggested that it is a problem for the account if the utterances in the example are assertoric to the hearer.
} 
Some may still find it more intuitive that being assertoric simpliciter equals being assertoric to the speaker. This is in any case compatible with the present accounts of being assertoric to speaker and hearer, respectively, except that being assertoric to the hearer is not the same as being taken by the hearer as an assertion, i.e. as assertoric to the speaker. But it is implausible to claim that communication fails because the hearer lacks the concept of an assertion, even in a case where the utterance is assertoric to both speaker and hearer. And then it is not so clear what theoretical work a concept of being assertoric simpliciter will do.

\author{
Department of Philosophy \\ Stockholm University
}

\title{
References
}

Armstrong, David M. (1993). A Materialist Theory of the Mind. London: Routledge. Austin, John Langshaw (1975). How to do Things with Words. 2nd ed. Oxford: Oxford University Press.

Bach, Kent and R M Harnich (1979). Linguistic Communication and Speech Acts. Cambridge, Mass.: MIT Press.

Bovens, Luc and Stephan Hartmann (2003). Bayesian Epistemology. Oxford: Oxford University Press.

Brandom, Robert (1994). Making it Explicit. Cambridge, Mass.: Harvard University Press.

Chisholm, Roderick (1957). Perceiving: A Philosophical Study. Ithaca, NY: Cornell University Press.

Davidson, Donald (1979). 'Moods and Performances'. In: Meaning and Use. Ed. by Avishai Margalit. Reprinted in Davidson 1984b, . Page references to the reprint. Dordrecht: Reidel.

- (1984a). 'Communication and Convention'. In: Inquiries into Truth and Interpretation. Oxford: Clarendon Press, pp. 265-80.

- (1984b). Inquiries into Truth and Interpretation. Oxford: Clarendon Press. 
DeRose, Keith (2002). 'Assertion, Knowledge and Context'. In: The Philosophical Review 111, pp. 167-203.

Douven, Igor (2006). 'Assertion, Knowledge and Rational Credibility'. In: Philosophical Review 115, pp. 449-85.

Dretske, Fred (1981). Knowledge and the Flow of Information. Cambridge, Mass.: MIT Press.

Dudman, V. H. (1992). 'Probability and Assertion'. In: Analysis 52, pp. 204-11.

Dummett, Michael (1981). Frege: Philosophy of Language. 2nd ed. Cambridge, Mass.: Harvard University Press.

Evans, Gareth (1982). The Varieties of Reference. Oxford. Edited by John McDowell.: Clarendon Press.

Frankish, Keith (2009). 'Partial Belief and Flat-Out Belief'. In: Degrees of Belief. Ed. by F. Huber and C. Schmidth-Petri. Dordrecht: Springer, pp. 75-93.

Garcia-Carpintero, Manuel (2004). 'Assertion and the Semantics of ForceMarkers'. In: The Semantics/Pragmatics Distinction. Ed. by Claudia Bianchi. CSLI Publications.

Glüer, Kathrin and Peter Pagin (1999). 'Rules of Meaning and Practical Reasoning'. In: Synthèse 117, pp. 207-27.

Goldberg, Sandy and David Henderson (2006). 'Monitoring and AntiReductionism in the Epistemology of Testimony'. In: Philosophy and Phenomenological Research 72, pp. 600-617.

Goldman, Alvin (1979). 'What is Justified Belief?' In: Justification and Knowledge. Ed. by G Pappas. Dordrecht: Reidel, pp. 1-23.

Grice, Herbert Paul (1957). 'Meaning'. In: The Philosophical Review 66, pp. 377-88. Hållsten, Henrik (2001). Deduction and Explanation. Stockholm Studies in Philosophy. Stockholm University, Stockholm: Acta Universitatis Stockholmiensis.

Hawthorne, John (2004). Knowledge and Lotteries. Oxford: Oxford University Press. Jackson, Frank (1977). Perception. A Representative Theory. Cambridge: Cambridge University Press.

Kaplan, Mark (1996). Decision Theory as Philosophy. Cambridge: Cambridge University Press. 
Kvanvig, Jonathan L. (2008). 'Assertion, Knowledge and Lotteries'. In: Williamson on Knowledge. Ed. by Patrick Greenough and Duncan Pritchard. Oxford: Oxford University Press.

Lackey, Jennifer (2007). 'Norms of Assertion'. In: Nous 41, pp. 594-626.

Lewis, David (1975). 'Languages and Language'. In: Language, Mind and Knowledge. Ed. by Keith Gunderson. Minnesota Studies in the Philosophy of Science VII. Minneapolis: University of Minnesota Press, pp. 3-35.

- (1979). 'Scorekeeping in a Language Game'. In: Journal of Philosophical Logic 8. Reprinted in Lewis 1983, 233-49. Page references to the reprint, pp. 339-59.

- (1983). Philosophical Papers. Volume I. Oxford: Oxford University Press.

Martin-Löf, Per (1998). 'Truth and Knowability. On the Principles $C$ and $K$ of Michael Dummett'. In: Truth in Mathematics. Ed. by H G Dales and Gianluigi Oliveri. Oxford: Clarendon Press, pp. 105-14.

Owens, David (2006). ‘Testimony and Assertion'. In: Philosophical Studies 130, pp. 105-29.

Pagin, Peter (1987). 'Ideas for a Theory of Rules'. PhD thesis. Stockholm University.

- (2004). 'Is Assertion Social?' In: Journal of Pragmatics 36, pp. 833-59. To be reprinted in Asa Kasher (ed.) Pragmatics: Critical Concepts II, Routledge, 2010.

- (2008). 'Informativeness and Moore’s Paradox'. In: Analysis 68, pp. 46-57.

- (2009). 'Assertion Not Possibly Social'. In: Journal of Pragmatics 41, pp. 256367.

Partee, Barbara H (1997). 'The Genitive. A Case Study. Appendix to Janssen 1997.' In: Handbook of Logic and Language. Ed. by Johan van Benthem and Alice ter Meulen. New York: Elsevier, pp. 464-70.

Pollock, John (1974). Knowledge and Justification. Princeton, N.J. and London: Princeton University Press.

Recanati, François (1987). Meaning and Force. The Pragmatics of Performative Utterances. Cambridge: Cambridge University Press.

Reid, Thomas (1975). 'An Inquiry into the Human Mind on the Principles of Common Sense'. In: Thomas Reid's Inquiry and Essays. Ed. by R Beanblossom and K Lehrer. Indianapolis: Bobbs-Merrill, pp. 1-125. 
Reynolds, Stephen L. (2002). 'Testimony, Knowledge, and Epistemic Goals'. In: Philosophical Studies 110, pp. 139-61.

Searle, John (1969). Speech Acts. An Essay in the Philosophy of Language. Cambridge: Cambridge University Press.

Slote, Michael A (1979). 'Assertion and Belief'. In: Papers on Language and Logic. Ed. by Jonathan Dancy. Keele: Keele University Library, pp. 177-90.

Sperber, Dan and Deirdre Wilson (1995). Relevance. Communication \& Cognition. 2nd ed. Oxford: Blackwell.

Stainton, Robert J (1997). 'What Assertion is Not'. In: Philosophical Studies 85, pp. 57-73.

Stalnaker, Robert (1999). Context and Content. Oxford: Oxford University Press.

Stanley, Jason (2005). Knowledge and Practical Interest. Oxford: Oxford University Press.

Stone, Jim (2007). 'Contextualism and Warranted Assertion'. In: Pacific Philosophical Quarterly 88, pp. 92-113.

Unger, Peter (1975). Ignorance. The Case for Skepticism. Oxford: Clarendon Press.

Weiner, Matthew (2005). 'Must We Know What We Say?' In: The Philosophical Review 114 , pp. 227-51.

Williamson, Timothy (1996). 'Knowing and asserting'. In: The Philosophical Review 105, pp. 489-523.

- (2000). Knowledge and its Limits. Oxford: Oxford University Press.

Wittgenstein, Ludwig (1980). Remarks on the Philosophy of Psychology. Vol. I. G.E.M. Anscombe and G.H. von Wright (eds). Basil Blackwell. 